\title{
New challenges in polymer foaming: A review of extrusion processes assisted by supercritical carbon dioxide
}

\author{
Martial Sauceau $^{\mathrm{a}, \mathrm{b}}$, Jacques Fages ${ }^{\mathrm{a}, \mathrm{b}, *}$, Audrey Common ${ }^{\mathrm{a}, \mathrm{b}}$, \\ Clémence Nikitine ${ }^{\mathrm{a}, \mathrm{c}}$, Elisabeth Rodier ${ }^{\mathrm{a}, \mathrm{b}}$
}

a RAPSODEE Research Centre, Ecole des Mines d'Albi, F-81013 Albi, France

b Université de Toulouse, Mines Albi, CNRS, F-81013 Albi, France

c Université de Lyon, CPE-LGPC, CNRS, F-69100 Villeurbanne, France

\begin{abstract}
A B S T R A C T
It is well known that supercritical carbon dioxide $\left(\mathrm{sc}-\mathrm{CO}_{2}\right)$ is soluble in molten polymers and acts as a plasticizer. The dissolution of $\mathrm{sc}-\mathrm{CO}_{2}$ leads to a decrease in the viscosity of the liquid polymer, the melting point and the glass transition temperature. These properties have been used in several particle generation processes such as PGSS (particles from gas saturated solutions).

It is therefore highly likely that extrusion processes would benefit from the use of sc- $\mathrm{CO}_{2}$ since the rationale of the extrusion processes is to formulate, texture and shape molten polymers by forcing them through a die. Combining these two technologies, extrusion and supercritical fluids, could open up new applications in extrusion.

The main advantage of introducing $\mathrm{sc}-\mathrm{CO}_{2}$ in the barrel of an extruder is its function as a plasticizer, which allows the processing of molecules which would otherwise be too fragile to withstand the mechanical stresses and the operating temperatures of a standard extrusion process. In addition, the dissolved $\mathrm{CO}_{2}$ acts as a foaming agent during expansion through the die. It is therefore possible to control pore generation and growth by controlling the operating conditions.

This review focuses on experimental work carried out using continuous extrusion. A continuous process is more economically favourable than batch foaming processes because it is easier to control, has a higher throughput and is very versatile in the properties and shapes of the products obtained.

The coupling of extrusion and supercritical $\mathrm{CO}_{2}$ technologies has already broadened the range of application of extrusion processes. The first applications were developed for the agro-food industry 20 years ago. However, most thermoplastics could potentially be submitted to sc- $\mathrm{CO}_{2}$-assisted extrusion, opening new challenging opportunities, particularly in the field of pharmaceutical applications.

This coupled technology is however still very new and further developments of both experimental and modelling studies will be necessary to gain better theoretical understanding and technical expertise prior to industrial use, especially in the pharmaceutical field.
\end{abstract}

\section{Keywords:}

Extrusion

Supercritical carbon dioxide

Polymer foaming

\begin{abstract}
Abbreviations: ABS, acrylonitrile butadiene styrene; API, active pharmaceutical ingredient; CBA, chemical blowing agent; CFC, chlorofluorocarbon; CFD, computational fluid dynamics; CSTR, continuous stirred tank reactor; EC, ethylcellulose; HC, hydrocarbon; HCFC, hydrochlorofluorocarbon; HDPE, high density polyethylene; HFC, hydrofluorocarbon; HFC-134a, 1,1,1,2-tetrafluoroethane; HIPS, high impact polystyrene; $L / D$, length to diameter ratio; PBA, physical blowing agent; PC, polycarbonate; PDMS, polydimethylsiloxane; PE, polyethylene; PEO, polyethylene oxide; PGSS, particles from gas-saturated solutions; PLA, poly lactic acid; PMMA, polymethylmetacrylate; PP, polypropylene; PS, polystyrene; PVC, polyvinylchloride; PVDF, polyvinylidene fluoride; PVP-VA, polyvinylpyrrolidone-co-vinyl acetate; LDPE, low density polyethylene; RTD, residence time distribution; SCF, supercritical fluid.
\end{abstract}

\footnotetext{
* Corresponding author at: RAPSODEE Research Centre, Ecole des Mines d'Albi, F-81013 Albi, France. Tel.: +33 563493141 ; fax: +33563493025. E-mail address: jacques.fages@mines-albi.fr (J. Fages).
} 


\section{Contents}

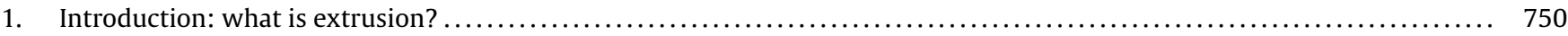

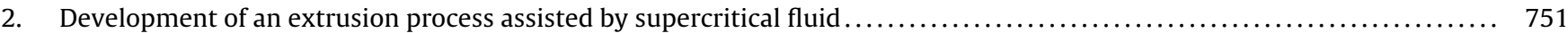

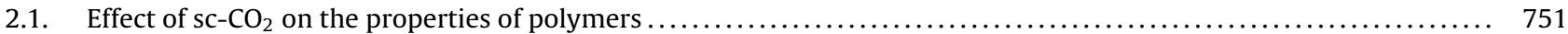

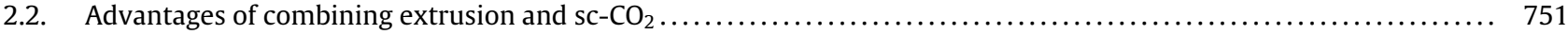

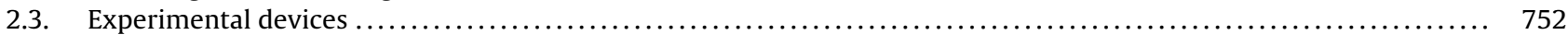

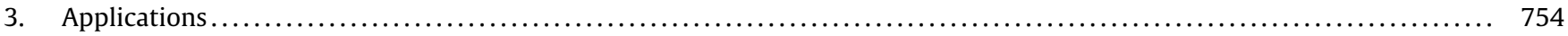

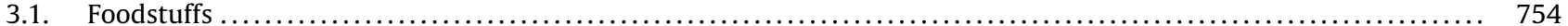

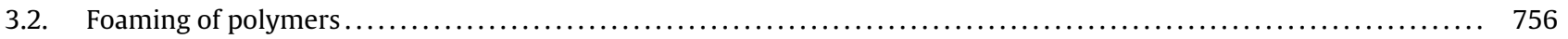

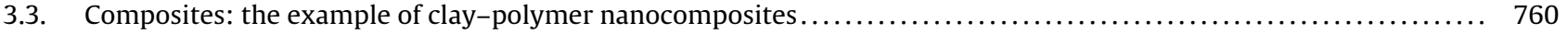

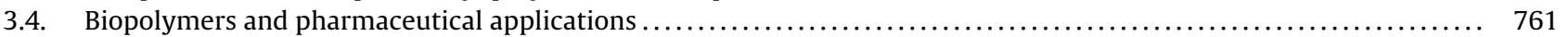

4. Conclusion: assisting extrusion process by supercritical $\mathrm{CO}_{2}$ extends the field of application and opens new opportunities .. 764

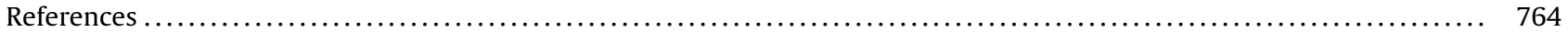

\begin{tabular}{|c|c|}
\hline \multicolumn{2}{|c|}{ Nomenclature } \\
\hline \multicolumn{2}{|l|}{ Symbols } \\
\hline$f_{\mathrm{h}}$ & frequency factor \\
\hline$C_{\mathrm{h}}$ & gas concentration \\
\hline$k_{\mathrm{B}}$ & Boltzmann constant \\
\hline$N_{\mathrm{h}}$ & $\begin{array}{l}\text { number of pores created per unit of time } \\
\text { and volume }\end{array}$ \\
\hline$P$ & pressure \\
\hline$P_{\mathrm{c}}$ & critical pressure \\
\hline $\mathrm{sc}-\mathrm{CO}_{2}$ & supercritical carbon dioxide \\
\hline$T$ & temperature \\
\hline$T_{\mathrm{c}}$ & temperature \\
\hline$T_{\mathrm{g}}$ & glass transition temperature \\
\hline \multicolumn{2}{|c|}{ Greek symbols } \\
\hline$\sigma$ & $\begin{array}{l}\text { interfacial tension between the polymer } \\
\text { and the gas }\end{array}$ \\
\hline$\Delta G_{\mathrm{h}}^{*}$ & $\begin{array}{l}\text { free energy for formation of gas critical } \\
\text { nucleus }\end{array}$ \\
\hline$\Delta P_{\mathrm{i}}$ & $\begin{array}{l}\text { degree of supersaturation, equal to the } \\
\text { difference between the nucleating phase } \\
\text { pressure as it would be in the bulk at the } \\
\text { same temperature and chemical potential } \\
\text { of the system and the actual pressure within } \\
\text { the system }\end{array}$ \\
\hline
\end{tabular}

\section{Introduction: what is extrusion?}

To extrude means to force a material through a restricted orifice often called a die [1]. Therefore an extruder is basically composed of one or two rotating Archimedes screws fitted in a barrel in order to progressively increase the pressure and push forward the ingredients through a die where expansion takes place. Thermo-mechanical treatments occurring in the barrel contribute to what is called the texturization of the product (initially in granular form) while the expansion in the die is responsible for the shaping of the end product. Screw profiles and dimensions (length over diameter ratio), screw speed, die size and shape, temperature, pressure, moisture content (or other plasticizer agent) are the most important parameters for controlling the process.

In spite of high operating temperatures (up to $200^{\circ} \mathrm{C}$ ) and pressures (over $10 \mathrm{MPa}$ ) as well as high shear rates, the processing of polymers by extrusion, also known as hot-melt extrusion, is a widely used process in industry because it is a continuous quick, simple and versatile operation for transforming raw ingredients into finished products.

The polymer industry has been using extrusion for decades as a high volume manufacturing process to produce many different items such as tubes, frames, plastic sheets and films [1]. It has also been used for a considerable number of years in the food industry with starchy materials and protein based polymers and it is probably the most universally well-known extrusion process in pasta manufacturing [2]. The water always present in these products explains why this process is also referred as a steam-based extrusion cooking.

Melt extrusion has been used by the pharmaceutical industry for decades to make solid dispersions of poorly soluble drugs because such dispersions enhance bioavailability [3]. An active pharmaceutical ingredient (API) can thus be dispersed in a carrier to form various preparations including controlled-released dosage forms. Short residence time in the extruder, absence of organic solvents, easy scale-up and the possibility of operating as a continuous process are the most often cited advantages. High shear forces and temperatures are the main drawbacks to extrusion for these applications. The products obtained by extrusion can be processed further into tablets or capsules.

A particular application is polymeric foaming [4]. Foams are generally obtained by the addition of a chemical blowing agent (CBA). This agent, usually an organic compound with a low molecular weight, is mixed with a polymeric matrix. There is a temperature above which the nucleation agent is decomposed, a gas is produced and bubbles appear at the outlet of the die. This simple operation does not give good control of porosity and products often exhibit non-uniform cellular structures. This also implies the presence of residues in the final product and the need for an additional stage to eliminate them.

Physical blowing agents (PBAs) can also be used. Upon their vaporisation due to a change in pressure and temperature, these agents create porosity in the final product. Currently, the focus is on $\mathrm{CO}_{2}$ due to its relative ease of handle and more favourable interaction with polymers compared to other inert gases. Moreover, traditional PBAs like chlorofluorocarbons (CFCs) and hydrochlorofluorocarbons (HCFCs) are known for their contribution to the depletion of the ozone layer. Further, hydrofluorocarbons 


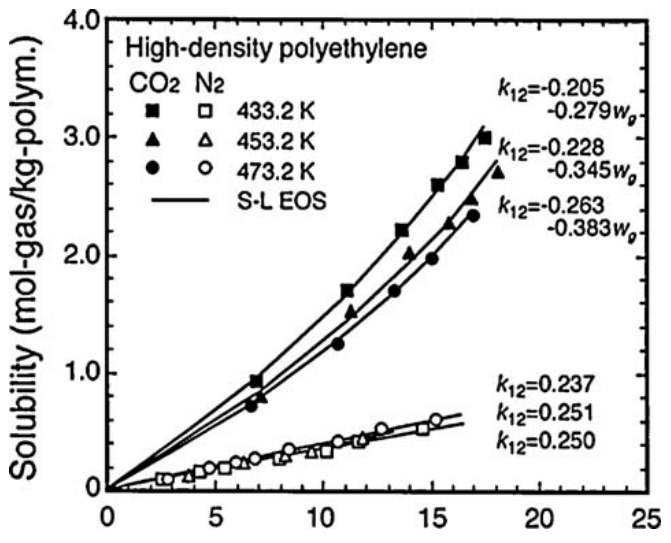

Fig. 1. Solubility in HDPE of $\mathrm{CO}_{2}$ and $\mathrm{N}_{2}$ [11]. Copyright by Elsevier, 1999.

(HFCs) aggravate the greenhouse effect and hydrocarbons (HCs) pose hazard due to their high flammability [5].

\section{Development of an extrusion process assisted by supercritical fluid}

\subsection{Effect of $s c-\mathrm{CO}_{2}$ on the properties of polymers}

A supercritical fluid (SCF) is defined as a substance for which both pressure and temperature are above their critical values. It has properties intermediate between those of gases and liquids [6]. Supercritical carbon dioxide is most often used because it is non-toxic, non-flammable, chemically inert, and its supercritical conditions are easily reached $\left(T_{\mathrm{C}}=31^{\circ} \mathrm{C}, P_{\mathrm{C}}=7.38 \mathrm{MPa}\right)$. Sc $-\mathrm{CO}_{2}$ is often used in polymer processing [7-10]. The special combination of gaslike viscosity and liquid-like density makes it an excellent solvent or plasticizer in these applications, e.g., polymer composites, microcellular foaming or particle production.

To illustrate favourable interactions of $\mathrm{sc}-\mathrm{CO}_{2}$ in comparison with other inert gases, Fig. 1 compares solubility of $\mathrm{N}_{2}$ and $\mathrm{CO}_{2}$ in high density polyethylene (HDPE) [11]. Solubility increases with pressure for both gases but $\mathrm{N}_{2}$ solubility increases with temperature unlike that of $\mathrm{CO}_{2}$. However, it has to be noted that solubility of $\mathrm{N}_{2}$ remains lower than that of $\mathrm{CO}_{2}$ for all operating conditions.

The high solubility enhances plasticizing and expansion of a material, with accompanying modification of mechanical and physical properties. For example, $\mathrm{CO}_{2}$ decreases the glass transition temperature, $T_{\mathrm{g}}$, and the viscosity of many polymers without otherwise changing their pseudoplastic behavior [12,13]. Wang and co-workers studied the effect of $\mathrm{CO}_{2}$ in the pressure range $0.1-105 \mathrm{MPa}$ on the Young's modulus and the glass transition temperature of polystyrene (PS). They were the first to report the severe plasticization effect of sc- $\mathrm{CO}_{2}$ on this polymer [14]. Condo et al. showed that the $T_{\mathrm{g}}$ of PS can be reduced from $105^{\circ} \mathrm{C}$ to $98^{\circ} \mathrm{C}$ with $1 \%$ mass of $\mathrm{CO}_{2}$ and to $46.4{ }^{\circ} \mathrm{C}$ with 5.9\% [15]. Using novel equipment, Royer et al. [16] showed that the presence of $\mathrm{CO}_{2}$ can reduce the viscosity of poly(dimethylsiloxane) (PDMS) by up to a factor of 100. This effect is also illustrated in Fig. 2 for low density polyethylene (LDPE), for which a $30 \%$ decrease in viscosity is observed with an increase of the concentration of $\mathrm{CO}_{2}$ (and consequently pressure) [17].

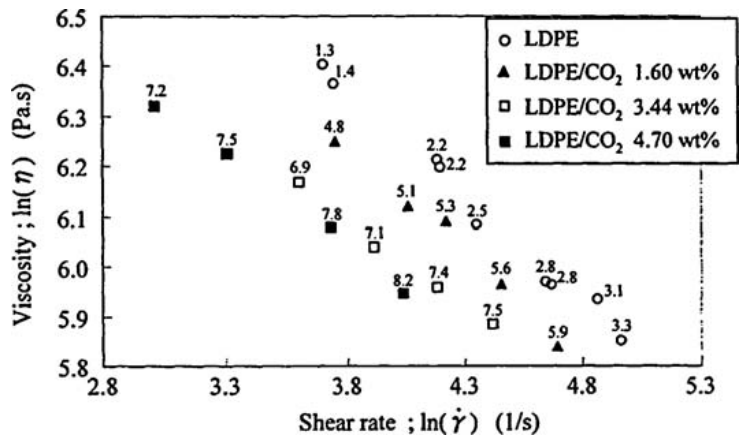

Fig. 2. Viscosity of $\mathrm{LDPE} / \mathrm{CO}_{2}$ mixtures vs. shear rate (values indicated correspond to pressure in MPa) [17]. Copyright by Wiley, 2002.

Lee et al. studied the viscosity of a mixture PE/PS in $80 / 20$ mass ratio [18]. The viscosity decreases when the $\mathrm{CO}_{2}$ concentration rises. Moreover, the pseudoplastic behavior of the mixture is reduced by the presence of $\mathrm{CO}_{2}$, which brings an increase in the power law index from 0.29 to 0.34 , whatever the $\mathrm{CO}_{2}$ concentration. The authors compared this increase with that obtained by the temperature effect. Indeed, a rise in temperature or a dissolution of a gas in the polymer shows the same effect on viscosity.

A lower consistency index and a higher flow index were also observed with the increase of the $\mathrm{sc}-\mathrm{CO}_{2}$ ratio for blends of pregelatinized corn starch and whey protein isolates with five protein concentrations (0-18wt\%) [19]. It was explained by an increase in the polymer free volume, which results in a dilution of the concentration of entangled polymer chains, leading to larger $n$ value and subsequently reduced shear thinning behavior.

The interfacial tension of polymers is also reduced by increasing fluid pressure and temperature [20]. Fig. 3 illustrates the effect of the saturation pressure of both $\mathrm{N}_{2}$ and $\mathrm{CO}_{2}$ on the interfacial tension of styrene [21]. The general tendencies are confirmed, but the decrease is much larger in the case of $\mathrm{CO}_{2}$ than that observed with $\mathrm{N}_{2}$.

\subsection{Advantages of combining extrusion and $\mathrm{sc}-\mathrm{CO}_{2}$}

In an extrusion process, $\mathrm{sc}-\mathrm{CO}_{2}$ will change the rheological properties of the material inside the extruder and will play the role of an expansion agent [22-24]. The diminution of viscosity will result in the limitation of mechanical

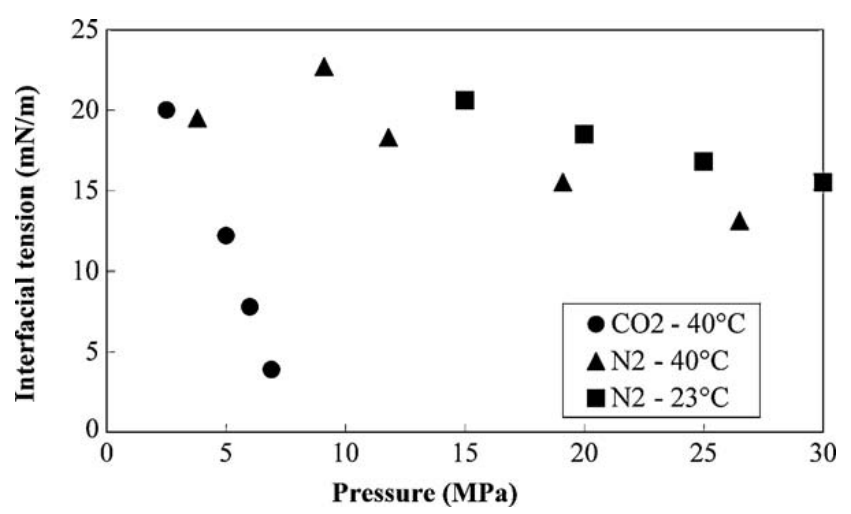

Fig. 3. Interfacial tension of styrene under pressure of $\mathrm{N}_{2}$ and $\mathrm{CO}_{2}$ [21]. Copyright by Elsevier, 2002. 
stresses and a decrease in operating temperatures. It will also allow handling molecules having a limited thermal stability. Moreover, its dissolution in the polymer under pressure will be accompanied by large volume expansion during the return to atmospheric pressure.

The use of $\mathrm{sc}-\mathrm{CO}_{2}$ as a blowing agent during the extrusion of food products uncouples the dual role of water as a blowing agent and a plasticizer since the product can be puffed at the die by the $\mathrm{CO}_{2}$, at temperatures less than $100{ }^{\circ} \mathrm{C}$. In addition, throughput can be increased at a lower moisture content and the formation of steam during pressure reduction can be prevented [25].

On the other hand, a higher moisture content could be used to keep the product temperature low via the reduction of viscous dissipation of energy and to maximize the solubility of $\mathrm{sc}-\mathrm{CO}_{2}$ in the melt. This higher moisture content in the melt reduces the glass transition temperature of the product and the extrudates are in rubbery state when leaving the die with a low enough viscosity to cause pore evolution [26]. This leads to a unique time-delayed expansion. Whereas the typical time for extrudate expansion in conventional steam-based extrusion is less than $0.5 \mathrm{~s}$, in this case it takes up to 3-20 s to attain maximum expansion with sc- $\mathrm{CO}_{2}$.

The reduction of the glass transition temperature, $T_{\mathrm{g}}$, is also very important for many amorphous polymers. Indeed, during expansion, $T_{\mathrm{g}}$ increases with evaporation of $\mathrm{CO}_{2}$, and thus reaches the temperature at which the structure is solidified and cannot continue expanding. The expanded material can therefore be built up at constant temperature by means of a rapid pressure drop provoking phase separation of polymer- $\mathrm{CO}_{2}$ mixture. This is opposite to the method based on the temperature drop of the polymer previously dissolved in an appropriate solvent and heated high enough such that only one phase exists [27].

Another specificity of such process is that both the quantity of sc- $\mathrm{CO}_{2}$ dissolved and the pressure drop can be controlled by adjusting the operating conditions. Consequently, the expansion, size, and density of pores can be fixed so as to obtain materials with a wide range of mechanical properties.

The initial stage of the formation of gas bubbles from the initial metastable polymer melt phase is called nucleation. During this step, a gas bubble must overcome a free energy barrier before it can grow to a macroscopic size. This stage is commonly described by the classical nucleation theory [28]. The homogeneous nucleation rate $N_{\mathrm{h}}$ is defined as the number of pores created per unit of time and volume. According to the classical theory, it can be expressed as:

$N_{\mathrm{h}}=f_{\mathrm{h}} C_{\mathrm{h}} \exp \left(-\frac{\Delta G_{\mathrm{h}}^{*}}{k_{\mathrm{B}} T}\right)$

where $f_{\mathrm{h}}$ is the frequency factor, $C_{\mathrm{h}}$ is the gas concentration, $k_{\mathrm{B}}$ is Boltzmann constant, $T$ is the temperature and $\Delta G_{\mathrm{h}}^{*}$ is the free energy for formation of gas critical nucleus, defined as:

$\Delta G_{\mathrm{h}}^{*}=\frac{16 \pi \sigma^{3}}{3 \Delta P_{\mathrm{i}}^{2}}$
Here, $\sigma$ is the interfacial tension between the polymer and the gas, $\Delta P_{\mathrm{i}}$ is the degree of supersaturation, equal to the difference between the nucleating phase pressure as it would be in the bulk at the same temperature and chemical potential of the system and the actual pressure within the system [5]. Diminishing the surface tension or increasing the supersaturation degree will result in the increase of the nucleation rate and the number of bubbles created. At the same time, the fact the surface tension is to the third power in the expression of free energy will result in a higher influence on nucleation. Thus, the reduction of interfacial tension with pressure (Fig. 3), by sc- $\mathrm{CO}_{2}$ allows the bubbles to appear at the minimum surface energy. This causes a more rapid and homogeneous nucleation, and thus creates a finer pore structure.

Han et al. [29] calculated this nucleation rate on the basis of the classical nucleation theory for a mixture of polystyrene (PS) and $\mathrm{CO}_{2}$. Varying different parameters by $\pm 1 \%$ in relation to their average values ( $C_{\mathrm{h}}$ to $3 \%, \sigma$ to $0.0173 \mathrm{~N} \mathrm{~m}^{-1}, \Delta P_{\mathrm{i}}$ to $16 \mathrm{MPa}$ and $T$ to $100{ }^{\circ} \mathrm{C}$ ), confirmed the importance of the interfacial tension and of the saturation pressure on the nucleation rate [30-33].

Several studies used classical nucleation theory to predict bubble nucleation in thermoplastic polymers [27,28,30-33]. Recently, Shukla and Koelling reconciled theory and experimental observations by applying a correction to the surface tension to override the capillary approximation in the classical theory [34]. However, there is a considerable uncertainty in the classical prediction of the homogeneous nucleation rate due to the inaccurate experimental determination of the key quantities [5]. As emphasized by the authors, the limitation of this theory is rather in the determination of these parameters than in its thermodynamic foundation.

Ideal conditions for a homogeneous nucleation are scarcely obtained in practice and thus it is difficult to avoid heterogeneous nucleation. However, it has been difficult to predict the potential role of heterogeneous nucleation due to the lack of an appropriate model describing the interaction between the polymer-gas mixture and the heterogeneous surface. Recent theoretical developments show great promise, e.g., a self-consistent field theory of foam formation using $\mathrm{CO}_{2}$ [5].

Visual observations of batch and continuous foaming processes have been conducted to better understand bubble nucleation and growth behavior in polymers [35,36]. It was found that the nucleation mechanism in continuous foaming, i.e., extrusion foaming, was different than that for batch foaming. In the continuous extrusion foaming, the nucleation could be induced by flow and/or shear stress, and by cavitation brought by the surface roughness of the wall.

\subsection{Experimental devices}

The experimental device must allow the following steps:

- Feeding of the components (dosing and conveying granules or powders); 


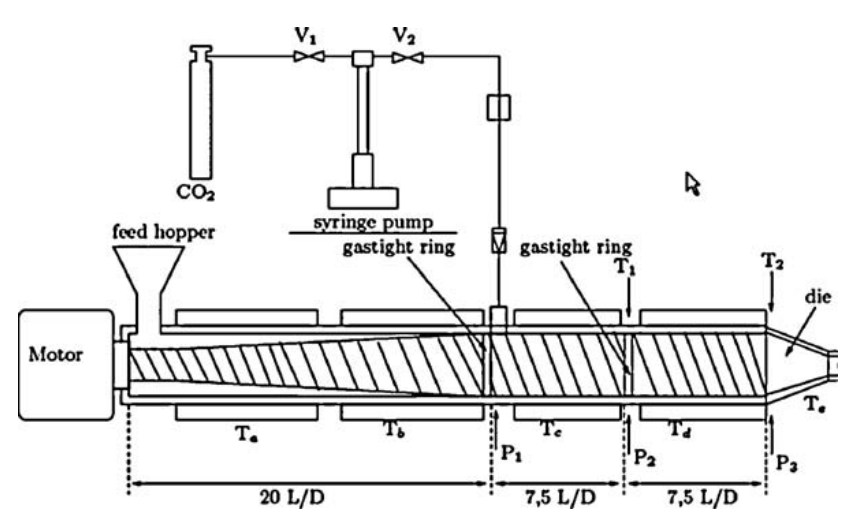

Fig. 4. Experimental device [37-40].

- development of rheological properties of the melt (preparation and plasticizing);

- injection of pressurised $\mathrm{CO}_{2}$;

- homogeneous mixing to obtain a single phase mixture;

- nucleation, growth and coalescence of pores provoked and controlled by the thermodynamic instability created by the pressure drop through the die;

- material shaping and cooling at the return to atmospheric pressure.

As an example, Fig. 4 shows the experimental set up used by Fages and co-workers [37-40]. The single-screw extruder used in this study had a $30 \mathrm{~mm}$-screw diameter and a length to diameter ratio $(L / D)$ of 35 , that is to say a $1.05 \mathrm{~m}$ length (Rheoscam, SCAMEX). The screw was divided into three sections. The first has a length to diameter ratio of 20 and the two others have a length to diameter ratio of 7.5. A restriction ring was located between each section to increase the pressure locally, creating thus a dynamic molten polymer seal, which prevents backflow of $\mathrm{sc}-\mathrm{CO}_{2}$. The first section is conical for the transport of the solid polymer and its melting and plasticizing. The final sections of the screw have a cylindrical geometry from the first gastight ring to the die. The temperature inside the barrel is regulated at five locations: $T_{\mathrm{a}}$ and $T_{\mathrm{b}}$ before the $\mathrm{CO}_{2}$ injection, $T_{\mathrm{c}}$ and $T_{\mathrm{d}}$ after the injection and $T_{\mathrm{e}}$ in the die.

The polymer is introduced into the feed hopper, and then flows through the barrel, begins to melt in the first section, is pressurized in the last two sections and is then forced through the die. There are three pressure sensors and two temperature sensors: $P_{1}, P_{2}$ and $T_{1}$ before the gastight rings and $P_{3}$ and $T_{3}$ before the die. This allows measuring the temperature and the pressure of the polymer inside the extruder. Carbon dioxide is pumped from a cylinder by a syringe pump operating in constant volumetric flow rate mode, which allows small constant flow rates (down to $1 \mu \mathrm{lmin}^{-1}$ ). The $\mathrm{CO}_{2}$ was introduced at the same pressure as the polymer in the extruder by an injector positioned at a length to diameter ratio of 20 from the feed hopper. This point corresponds to the beginning of the metering zone where the channel depth is constant and equal to $15 \mathrm{~mm}$.

The pressure, the temperature and the volumetric $\mathrm{CO}_{2}$ flow rate are measured within the syringe pump. $\mathrm{CO}_{2}$ density could be obtained by an equation of state $[41,42]$.

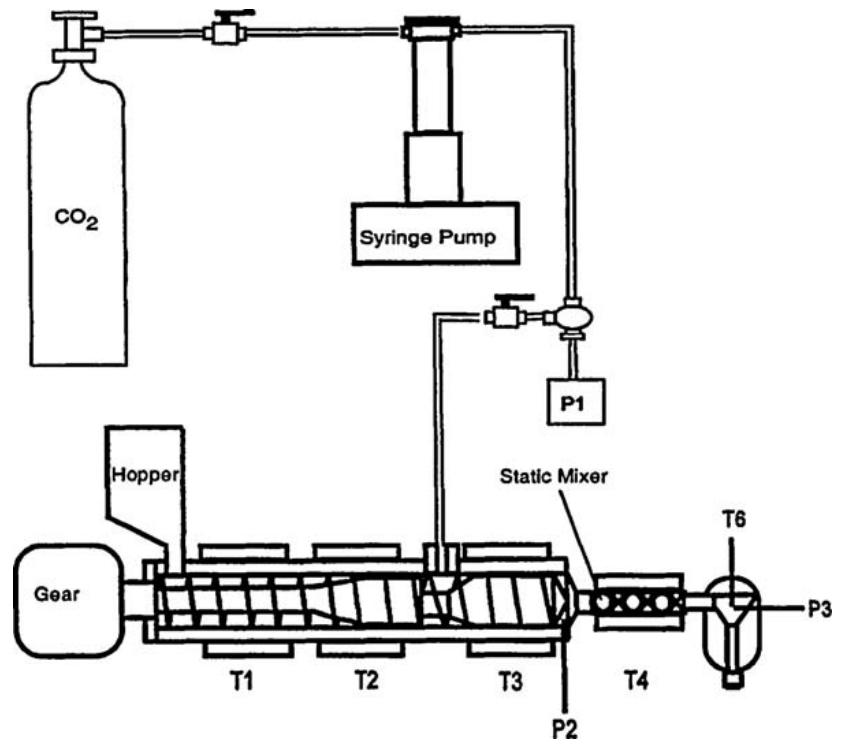

Fig. 5. Experimental setup of foaming extrusion [29,44]. Copyright by Wiley, 2002.

For each experiment, steady-state conditions were first established without $\mathrm{CO}_{2} \cdot \mathrm{CO}_{2}$ was then introduced by keeping the pressure in the $\mathrm{CO}_{2}$ pump slightly higher than the pressure $P_{1}$, measured at the injection point within the barrel. Once steady state conditions are reached, extrudates are collected and cooled in order to freeze the structure of the polymer.

It is also possible to add other devices to the end of the extruder. For instance, Park et al. [43] have used an experimental device consisting of a $20 \mathrm{~mm}$ single screw extruder followed by a diffusion-enhancing device and a heat exchanger containing static mixers for cooling the polymer melt. The $\mathrm{CO}_{2}$ was injected by means of a positive displacement pump and a rapid-pressure-drop obtained by means of a nozzle die with a diameter of $0.46 \mathrm{~mm}$ and a length of $2.54 \mathrm{~mm}$.

Han et al. $[29,44]$ carried out their experiments on a two stage single screw extruder. The screw had a diameter of $20 \mathrm{~mm}$ and a $L / D$ ratio of $25 . \mathrm{CO}_{2}$ was injected in the barrel from a port initially designed for venting located between the two screw stages where the barrel pressure is relatively low (Fig. 5). As previously described, a static mixer was also attached to the end of the extruder to provide extra mixing. Finally, a capillary die, with a $0.5 \mathrm{~mm}$ diameter and $10 \mathrm{~mm}$ length nozzle, was custom made to generate high and rapid pressure drop.

Rizvi and co-workers have developed several processes using a co-rotating twin screw extruder with a $52 \mathrm{~mm}$ screw diameter (Wenger TX52) [25,26,45-57]. The screw configuration and $L / D$ ratio were varied according to the application. A pilot scale supercritical fluid system was used for injecting sc- $\mathrm{CO}_{2}$ at a constant flow rate. In order to force the sc- $\mathrm{CO}_{2}$ to move forwards and not backwards after injection, a pressure block was fitted before the injection site by reverse screw elements. A flow restrictor plate was installed on the outlet from the last barrel and before the die assembly to maintain and regulate pressure. More recently, the authors developed a visualization technique to determine expansion profile as a function of time [58] 
and an online slit die rheometer to measure the rheological properties [19].

Verreck et al. have performed hot stage extrusion tests using a co-rotating intermeshing twin-screw extruder [59-62]. The screw diameter was $18 \mathrm{~mm}$ and the $L / D$ ratio was 40 . The physical mixture was fed with a K-Tron lossin-weight feeder system (K-Tron, Switzerland). Carbon dioxide was pressurized and injected into the extruder through an injection nozzle using a syringe pump (260D, Isco), operating at a constant pressure.

In 2004, Benkreira et al. presented a new roller die design capable of generating high pressures to allow the direct injection of liquid carbon dioxide into polymer melts and produce low density foams [63]. The novelty of the design lies in the counter-flow action of a pair of rotating rollers separated by a gap to build up pressure. A mathematical model of the flow in the extrusion-roller die system was developed and tested against experimental data with PS, LDPE and PP under a wide range of roller speeds and gaps. The study showed that this new design is feasible but more comprehensive CFD simulations and experiments are required to optimize design and operation to obtain the low-density polymer foams sought-after.

Several $\mathrm{CO}_{2}$-based mixtures have also been used as blowing agent. For instance, Champagne et al. used ethanol and 1,1,1,2-tetrafluoroethane (HFC-134a) as a co-blowing agent for the foaming of PS [64] and PE [65], respectively.

\section{Applications}

\subsection{Foodstuffs}

Extrusion is a widely used industrial technology for continuous production of expanded products such as breakfast cereals and snack foods. The steam-based conventional method in which water acts as a plasticizer and a blowing agent, involves high temperatures $\left(130-170^{\circ} \mathrm{C}\right)$ and shear, and low moisture content (13-20\%). These extreme conditions prevailing during steam extrusion prevent the use of heat sensitive ingredients, such as proteins or flavourings. In addition, the expansion provided by supercritical $\mathrm{CO}_{2}$ is less explosive than the puffing that results from the conversion of water into steam, resulting in a product with a smoother surface and regularly shaped pores. Steam-expanded products have a coarse and non-uniform cellular structure with cell sizes in the range of $1-3 \mathrm{~mm}$ and expansion ratio (bulk polymer density over apparent extrudate density) in the range of 9-12 [26]. Moreover, there is little or no control over cell size and density. New approaches are thus necessary to overcome these limitations, leading to a new generation of foods with improved characteristics.

The first reported use of the injection of $\mathrm{CO}_{2}$ into the barrel of an extruder, for any purpose, was published in 1990. Ferdinand et al. [66] studied the structure of different foodstuffs without steam expansion by injecting pressurized $\mathrm{CO}_{2}$ (from 1 to $5 \mathrm{MPa}$ ). This process led to a porous material with temperatures below $100^{\circ} \mathrm{C}$, but with lower expansion rate than when steam was used.

In 1992, Rizvi and Mulvaney [25] patented a novel extrusion technology for producing highly expanded starch in which $\mathrm{sc}-\mathrm{CO}_{2}$ was used as an expansion agent and to reduce the viscosity. In this process, the conventional functions of water as a plasticizer and expansion agent were separated. The temperature could thus be reduced to values less than $100^{\circ} \mathrm{C}$. $\mathrm{CO}_{2}$ was also considered for use as a transporting medium for sensitive constituents owing to its dissolving capability. This would permit either limiting the losses by introducing constituents later in the process or eliminating the supplementary stages for their introduction.

The Rizvi and Mulvaney patent was afterwards extended to other applications, such as cereals, flour products and derived processes, such as co-extrusion [45-47]. The cell structure differs from that obtained by steam expansion in most of the examples quoted. The new porous structure was generally closed, with a fine and regular porosity, and sometimes a smoother surface state (non porous skin). This was explained by a higher nucleation rate associated with more rapid nucleation limiting gas diffusion. This difference in structure results in reduced humidity absorption, better mechanical properties and improved homogeneity $[48,49]$.

During extrusion of breakfast cereals, Rizvi et al. were mainly interested in the characterization of the mixing between this foodstuff and sc- $\mathrm{CO}_{2}$. First, they investigated the residence time distribution (RTD) of a dye injected by means of $\mathrm{CO}_{2}$ [50], and then porosity was examined by image analysis [51]. The RTD of a reactor is a probability distribution function that describes the amount of time a fluid element spends inside the reactor [67]. The mean residence time (MRT) grew with pressure of material when $\mathrm{CO}_{2}$ was not used. With $\mathrm{CO}_{2}$ injection, the MRT did not change for low pressures ( 3 and $7 \mathrm{MPa}$ ), but increased for higher pressures (11 MPa). However, the average standard deviation of pore diameter increased with the $\mathrm{CO}_{2}$ pressure. The effect of the screw rotation speed (100, 150 and $200 \mathrm{rpm})$ was also studied at higher pressure. The MRT diminished with increasing rotation speed, this tendency being more pronounced for lower rotation speeds, whereas the average diameter of pores increased.

To complete their experimental study, the authors modelled the RTD and mixing. Three models were used to represent the experimental RTD [50]. A plug flow reactor in series with a cascade of CSTR gave the best results as this model has two parameters instead of one. The parameter related to the plug flow appeared to be proportional to $\mathrm{CO}_{2}$ injection pressure and to decrease non-linearly with increasing screw rotation speed.

Using mixing theories, the same authors were able to estimate the minimum time required to solubilize $\mathrm{CO}_{2}$ in the extruded foodstuff [51]. For the lowest pressures (3-7 MPa), this minimum time is lower than the characteristic time of the plug flow, which seems to be favourable to obtain a good mixing. However, it is not the case for the higher pressure (11 MPa), which seems to result in the reduction in mixing quality, even if the minimum time is lower than the mean residence time (MRT). Similarly, an increase of the screw rotation speed seemed to deteriorate the mixture quality. Afterwards, the authors linked the mixing quality to the pore size, having made the hypothesis that better mixing favours nucleation and thus smaller 

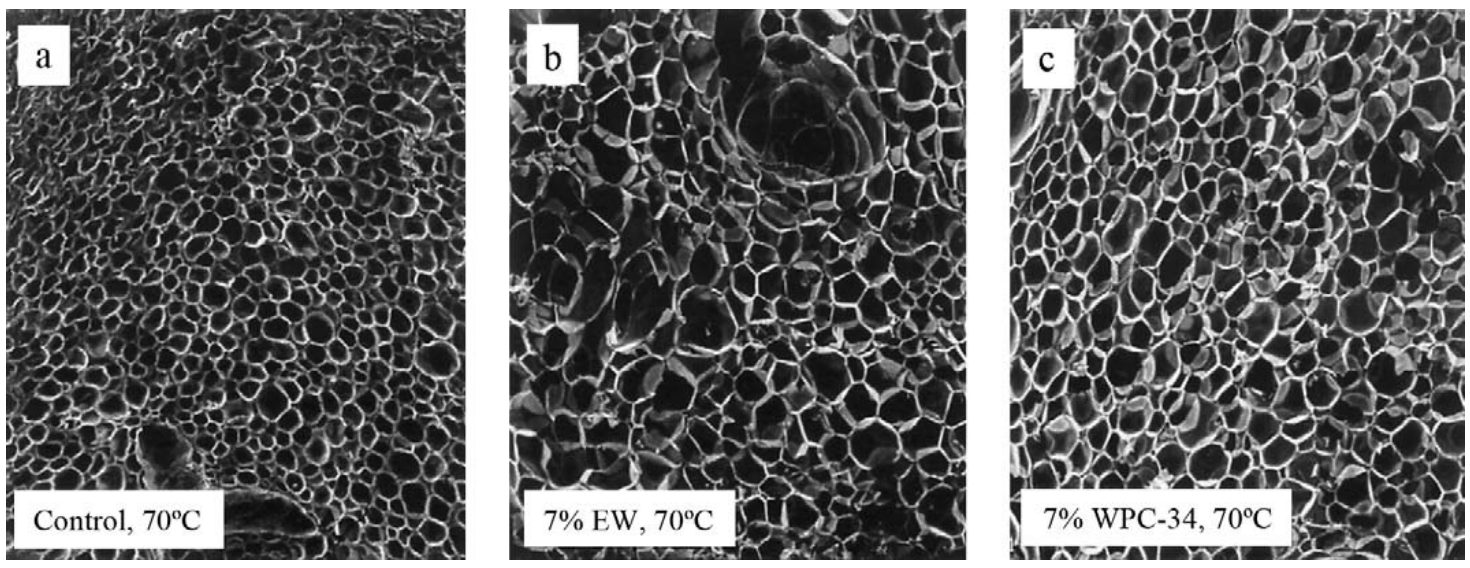

Fig. 6. Scanning electron micrographs (SEMs) of extrudates oven dried at $70{ }^{\circ} \mathrm{C}$; (a) control, (b) $7 \%$ egg white, (c) $7 \%$ whey protein concentrate $[26]$. Copyright by Elsevier, 1999.

pore size. Experimental results confirmed that the pore size increases with pressure and screw rotation speed [51].

Rizvi and co-workers observed a unique, time-delayed expansion for extrusion assisted with $\mathrm{sc}-\mathrm{CO}_{2}$. Whereas the typical time for extrudate expansion in conventional steam-based extrusion is less than $0.5 \mathrm{~s}$, in a supercritical process it takes from 3 up to $20 \mathrm{~s}$ to attain maximum expansion. Indeed, in order to maintain lower temperature, the moisture content of the material could be increased to reduce the viscosity and dissipation of heat by reducing the glass transition temperature $T_{\mathrm{g}}$ of the product. As a result, the extrudates are still in the rubbery state on exiting the die, and have low enough viscosity to cause cell growth during post-extrusion processes. For instance, a higher drying temperature enhanced growth phenomena and consequently the pore size and expansion of material $[26,52]$. This typical time-delayed expansion was studied by using video analysis with a mixture of starch and whey protein [58].

However, moisture content or drying temperature that were too high led to deterioration of the porous structure by shrinkage of the final product. This shrinkage can be attenuated by the addition of stabilizing agents, which harden the final product. These agents allow $T_{g}$ of material to increase at a faster rate during a pressure drop, and consequently increases the proportion of the pores frozen before reaching the critical size, thus reducing their destruction. However, the pore density is reduced. By using egg white protein and milk as stabilizing agent, Alavi et al. $[26,52]$ diminished the phenomenon of shrinkage in the extrusion of corn and potato starch (Fig. 6).

To achieve a better understanding of the role of the added agents in expansion and microstructure formation during supercritical assisted extrusion, Rizvi and co-workers examined the effects of rheological properties and process conditions on the expansion and 3D microstructure of a model starch/protein extrudates [19]. They noted that lowering the viscosity of protein added in the melt resulted in lower cell number density and decreased gas-holding capacity, as well as less crosssectional and volumetric expansion [19,56]. The effect of the formulation was also observed with starch-water mixtures with varying degree of starch gelatinization
[54] and starch solution reacted with epichlorohydrin [55].

Although sc- $\mathrm{CO}_{2}$ had a melt viscosity reduction effect, Cho and Rizvi found that the extrudate expansion increased with $\mathrm{sc}-\mathrm{CO}_{2}$ weight ratio [58]. The cell number density increased as did the pore size distribution with increase in sc- $\mathrm{CO}_{2}$ content [19]. The authors also calculated the pressure drop rate through the die with different $\mathrm{CO}_{2}$ concentrations [58]. They found that the pressure and the pressure drop rate in the die increased with the rise in $\mathrm{CO}_{2}$ concentration (from 0 to $0.75 \%$ ). This could be explained by the fact that the pressure was held constant at the end of the barrel. As a consequence, the higher the $\mathrm{CO}_{2}$ concentration, the smaller the pressure drop between the end of barrel and the die exit and the higher the pressure drop along the barrel. As previously observed by Park and co-workers [68,69], this higher pressure drop rate in the die and the increased amount of $\mathrm{CO}_{2}$ could be favourable for faster nucleation in the die. Cells that nucleated earlier continue to grow resulting in larger cell size in final foams compared to that of cells generated later, resulting in a less uniform cell size distribution.

However, significant structure collapse was also observed at higher sc- $\mathrm{CO}_{2}$ level, related to an early nucleation. Indeed, more premature cell generation results in severe gas release from the extrudate surface into the environment.

It has to be noted that an exceptionally small average cell size and a very high cell number density can be obtained depending on the coupling between the formulation and the amount of blowing agent [19]. As the authors calculated the lowest pressure drop rate in this case, they suggest that not only homogenous nucleation but also heterogeneous nucleation occurred. Due to their thermodynamic incompatibility, whey protein and starch exist as two separate phases. In consequence, the dispersed protein phase in a continuous starch matrix would act as a nucleating agent by inducing heterogeneous nucleation. Moreover, this hypothesis seems to be supported by the relatively high polydispersity, as a more uniform cell size distribution is expected with heterogeneous nucleation [19].

As previously observed for polymers ([43], detailed in Section 3.2), the high effective diffusivity of $\mathrm{CO}_{2}$ in 
the porous matrix favours the release of the gas to the environment, reducing the amount available for diffusion into the bubbles. To address this problem, Rizvi and coworkers have implemented two previously used methods (a) decreasing the nozzle diameter in order to achieve a higher pressure drop rate and thus increasing the nucleation rate, and (b) introduction of a cooling zone prior to the entry of the melt into the nozzle in order to reduce the melt temperature. Finally, bubble density increased when the nozzle radius decreased (from 5.9 to $2.9 \mathrm{~mm} \mathrm{[58]} \mathrm{and}$ from 3.00 to $1.50 \mathrm{~mm}$ [57]). A higher bubble density led to a greater barrier or resistance to diffusion of $\mathrm{CO}_{2}$ to the environment. The expansion ratio increased by $34 \%$ as the melt temperature dropped from 60 to $40^{\circ} \mathrm{C}$ [57]. Cooling of the melt resulted in a decrease in diffusion coefficient of $\mathrm{CO}_{2}$ in the starch melt, and thus reduced $\mathrm{CO}_{2}$ loss to the environment.

The production process of bread dough was also improved [53]. This provided a material with the same rheological properties as in the standard process, with the advantage of being much more rapid ( 5 min instead of $5 \mathrm{~h}$ ), avoiding alcohol production during the fermentation and having better retention of the added flavour. Therefore the specific mechanical energy consumed is more important (approximately 5 times more), resulting principally from the pressures applied during the extrusion process.

Another example was obtained with pre-gelatinized rice flour extrudates produced with a co-rotating twinscrew extruder with a $30 \mathrm{~mm}$ diameter and $L / D$ ratio of 25 under conditions for which no steam was generated to expand the extrudate [70]. The low temperatures of $40-60^{\circ} \mathrm{C}$ used in the process were relatively mild by extruder operating standards. Adequate expansion was achieved with $\mathrm{CO}_{2}$ injection to produce a highly porous product (approximately 74\%) at injection pressure less than 0.6 MPa. While producing less expanded structures compared to conventional steam expansion at high temperature, the low temperature extrusion process led to extrudates with adequate porosity and much improved water dispersibility.

\subsection{Foaming of polymers}

Conventional polymeric foams are very attractive mostly because of their lower cost per volume unit compared to unfoamed materials, but also for their properties of thermal and sound insulation, cushioning ability, etc. Foamed polymers are produced in a wide range of bulk density that mainly determine their mechanical properties, which are generally weaker than those of non porous materials, thus limiting the applications of foams. Microcellular foams, defined as foams with cell diameter lower than $10 \mu \mathrm{m}$ and cell density greater than $10^{9}$ cells $\mathrm{cm}^{-3}$ usually show better mechanical properties over conventional foams, making them highly competitive in many applications.

Many different polymers have been used for foaming purposes. Due to the numerous applications in foam packaging and insulation, polystyrene (PS) has been one of the polymers most studied. In 1998, low-density microcellular high impact polystyrene (HIPS) foams were successfully

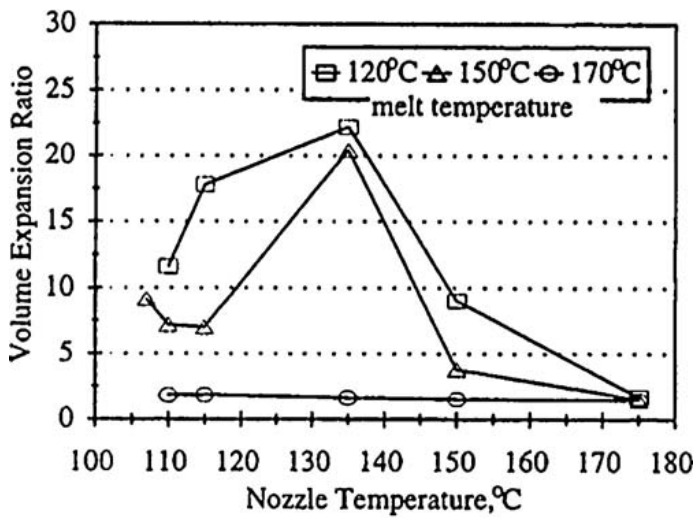

Fig. 7. Effect of the nozzle temperature on the volume expansion ratio [43]. Copyright by Wiley, 1998.

produced, with a cell density of $10^{10}$ cells $/ \mathrm{cm}^{3}$ and a controlled expansion ratio in the range of 1.5-23 [43] (Fig. 7). The basic approach for the process development was to first develop a high nucleated-cell density and then to promote a large volume expansion ratio while suppressing cell coalescence. Promotion of a large volume expansion ratio and a high cell-population density were obtained by preventing gas loss during expansion by freezing the extrudate surface (Fig. 8).

In order to prevent cell coalescence throughout the volume and to preserve the high cell density, uniform cooling of the polymer melt is required to increase melt strength before the melt enters the extrusion die. A large volume expansion ratio was achieved by freezing the extrudate surface at a reasonably low temperature of polymer melt because more gas was conserved in the foam to be used for cell growth. However, when the nozzle temperature was further decreased, the volume expansion ratio decreased because of the increased stiffness of the frozen skin layer. Finally, the volume expansion ratio of microcellular foamed HIPS could be controlled by tailoring the melt temperature, die temperature and injected gas content.

In 1999, Park et al. [71] patented a process allowing production of microcellular and super-microcellular polymers. Such products are defined by pore size less than $10 \mu \mathrm{m}$ and $1 \mu \mathrm{m}$ respectively, with densities higher than $10^{9}$ and $10^{12}$ pores $\mathrm{cm}^{-3}$. These materials present an improvement of the mechanical resistance to weight ratio.

Different polymers were tested on a $20 \mathrm{~mm}$ diameter single-screw extruder: polypropylene (PP), high impact

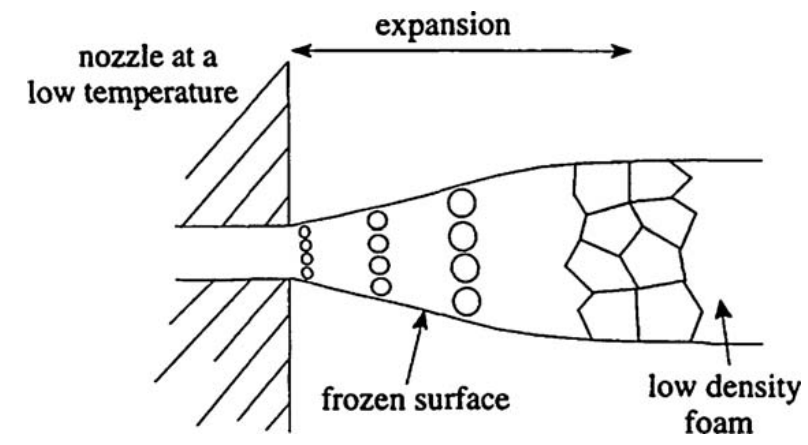

Fig. 8. Modelling of volume expansion in extruded foams [43]. Copyright by Wiley, 1998. 


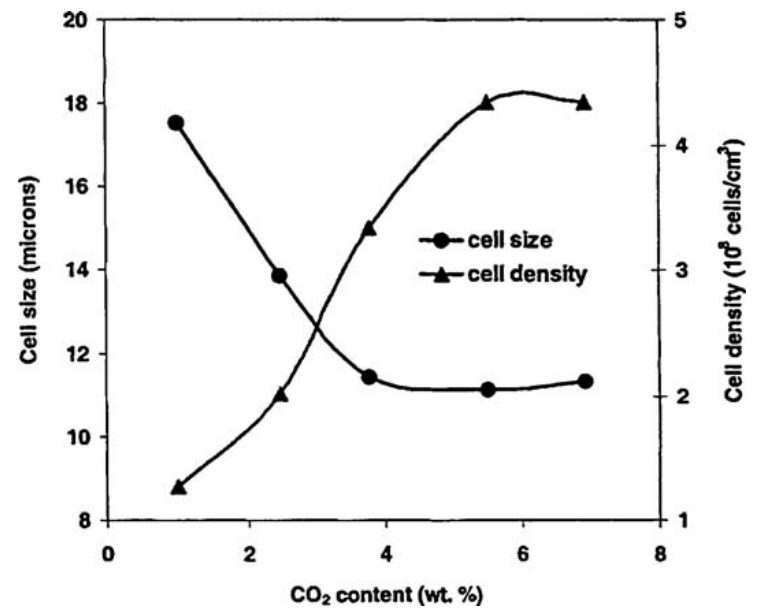

Fig. 9. Cell size and cell density affected by $\mathrm{CO}_{2}$ content (foaming temperature: $180^{\circ} \mathrm{C}$; screw rotation speed: $10 \mathrm{rpm}$ ) [44]. Copyright by Wiley, 2002.

polystyrene (HIPS) and acrylonitrile butadiene styrene (ABS). The effect of different parameters was studied on HIPS. The increase of the pressure drop $(\mathrm{d} P, 5.4-28.3 \mathrm{MPa}$ at the higher $\mathrm{CO}_{2}$ concentration), the $\mathrm{CO}_{2}$ concentration $(1-10 \%$ at $27.6 \mathrm{MPa})$ or the pressure drop rate $(\mathrm{d} P / \mathrm{d} t$, 0.18-6.9 $\mathrm{GPa} \mathrm{s}^{-1}$ with $10 \%$ of $\mathrm{CO}_{2}$ ) led to an increase of pore density (from $7 \times 10^{5}$ to $6 \times 10^{9}$ pores $\mathrm{cm}^{-3}$, from $1 \times 10^{7}$ to $6 \times 10^{9}$ and from $1 \times 10^{8}$ to $7 \times 10^{9}$ respectively).

More recently, the previously described surface cooling method was used in an extrusion-based open-cell foaming process with supercritical $\mathrm{CO}_{2}$ for thermoplastic polymers such as polystyrene (PS) and polycarbonate (PC) [72]. The effects of $\mathrm{CO}_{2}$ content, surface quenching, die geometry, and temperature on foam morphologies were investigated. Low-density, microcellular, open-cell foams were successfully produced.

In 2008, following their former work, Park and coworkers studied the effects of the die geometry on the expansion ratio of extruded foams with $\mathrm{CO}_{2}$ for PC [73], PP [68] and PS [69]. A strong relationship exists between the expansion ratio of the extruded foams and the die geometry through its effects on the pressure-drop rate, the die pressure, the amount of premature cell growth, and the initial shape of the extrudate. In particular, the amount of premature cell growth apparently played a critical role in determining the expansion ratio of the extrudate. The high pressure drop rate dies were favourable in promoting the expansion ratio. For each die geometry, there was an optimal temperature to maximize the expansion ratio (Fig. 7).

Han et al. studied production of microcellular polystyrene with a two-stage single screw extruder (20 mm diameter) $[29,44]$. They investigated the effect of the pressure, $\mathrm{CO}_{2}$ concentration [44], and die temperature [29] on the pore size and density. An increase in the pressure drop, the pressure drop rate, the $\mathrm{CO}_{2}$ concentration (up to $5 \%$ ) resulted in smaller pore size and higher cell density (Fig. 9). Above this $\mathrm{CO}_{2}$ concentration, the size and density no longer evolved, explained by the presence of $\mathrm{CO}_{2}$ in excess, which cannot influence the pore structure any more. Within the die temperature range from 160 to $240^{\circ} \mathrm{C}$, the pore size grew with temperature, whereas its density decreased. However, if the size and density of pores are represented as functions of pressure drop rate, the results obtained at different temperatures aligned on the same curve. This indicates that the size and density were more strongly correlated to pressure drop rate than to temperature.

The porosity structure was also modified by the operating parameters. An open porous structure was preferentially obtained at high temperature, high $\mathrm{CO}_{2}$ content and low screw rotation speed [29]. The authors explained this phenomenon by a higher pore growth, caused by a greater difference from glass transition temperature $T_{\mathrm{g}}$, due to the presence of gas, and by a longer residence time in the die.

These authors used CFD software to represent the pressure and temperature along the die, a tube of $7.8 \mathrm{~mm}$ internal diameter followed by a capillary with a length of $10 \mathrm{~mm}$ and an internal diameter of $0.5 \mathrm{~mm}$. An important hypothesis is that the $\mathrm{CO}_{2}$-PS mixture was always in single phase, viz., that the formation of the two phase mixture did not significantly affect the profile of the field variables. Other assumptions were a laminar, adiabatic and steady state flow and no slip conditions on the wall. In a first step, the pseudoplastic behavior of the mixture was taken into account by the model of Carreau for each $\mathrm{CO}_{2}$ concentration $[29,44]$. Later, the modelling was improved by using an internally consistent viscoelastic scaling approach [74]. In this approach, the temperature, pressure and $\mathrm{CO}_{2}$ concentration corrections on viscosity were accounted for independently through a combined shift factor, which is the product of the three individual shift factors. The Sanchez-Lacombe equation of state $[75,76]$ was used to calculate the density of the $\mathrm{CO}_{2}$-PS mixture, and also the solubility of $\mathrm{CO}_{2}$ in the PS along the die. This is the most used model for polymer $/ \mathrm{CO}_{2}$ systems [77].

The pressure drop was found to take place mainly along the capillary. At the same flow rate, a higher pressure led to a higher pressure drop rate, which plays an important role in determining the cell size and the cell density. A fairly good agreement is obtained between simulated and experimental pressures [74]. The pressure drop decreased with the increase of $\mathrm{CO}_{2}$ concentration [44], die temperature [29] or inlet melt temperature [74].

Moreover, the pressure profile along the capillary was highly nonlinear, the decrease rate being higher at the die entrance [74]. An important implication is that the saturation surface is shifted backwards the die entrance in comparison with a linear profile. The pressure contours were also obtained. They were found to become flat after a small entrance length in the die, implying that variation in pressure in the radial direction is negligible for all processing conditions studied [74]. A significant temperature increase was observed along and across the die section due to viscous heat dissipation near the wall of the capillary die. However, the heat generated near the wall did not have significant time to travel to the centre of the die [74]. The velocity profile assumed a flattened shape characteristic of shear-thinning polymer melts. However, a hump was observed at the entrance of the die, attributed by the authors to the redistribution of the velocity components just downstream from the contraction [74]. 
The authors also determined the position where nucleation took place, defined as a first approximation as the position at which the solution becomes supersaturated, and consequently where nucleation and growth could begin. This point of nucleation onset was determined as the point beyond which the calculated equilibrium solubility became lower than the experimental concentration. This position moved toward the entrance of the capillary as the $\mathrm{CO}_{2}$ concentration [44] (Fig. 10) die temperature [29] or inlet melt temperature [74] increased. The location of incipient nucleation was found to be very sensitive to the flow rate (screw rotation speed) at higher temperature [74], the position being moved toward the die exit by a flow rate increase. This means that increasing $\mathrm{CO}_{2}$ content or temperature led to an increased growth time. However, keeping in mind that two conditions are required to guarantee numerous pores of small size: high nucleation rate with a late nucleation (less growth), the complexity of the nucleation and growth phenomena did not permit a simple connection between the material structure and the nucleation position. The surface of nucleation onset had also shown that nucleation is induced first near the wall due to shear stress through viscous heat generation [74].

Hollow fibre membranes with interconnected open cells have been produced from polycarbonate by supercritical extrusion [78] (Fig. 11). The porous structure and the permeability were controllable by adjusting the amount of injected $\mathrm{CO}_{2}$ and the pressure- and temperature-profile in the extruder.

Another experimental device based on a single-screw extruder was developed by Sauceau et al. and applied to

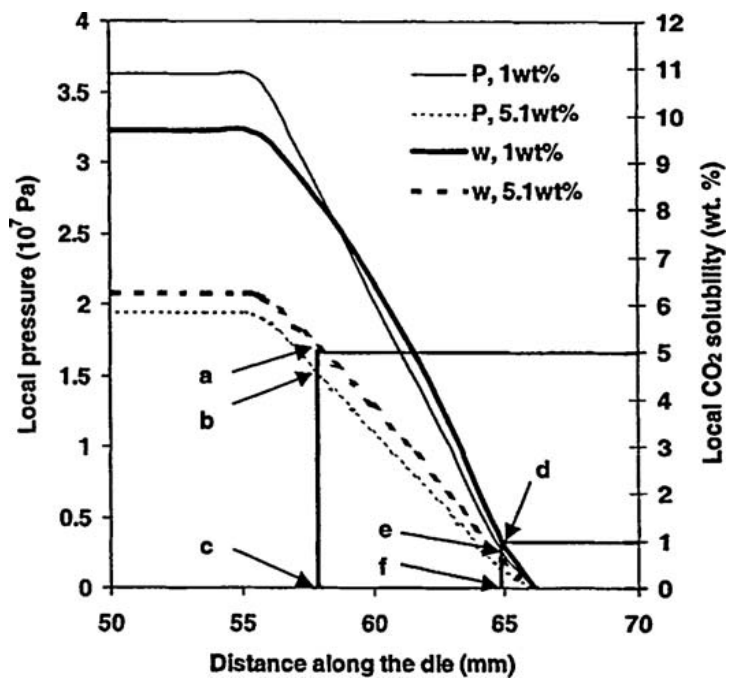

Fig. 10. Profiles of pressure and saturation $\mathrm{CO}_{2}$ weight fraction along the die nozzle with different $\mathrm{CO}_{2}$ content ( 1 and $5 \mathrm{wt} \%$ ) at the same die temperature $\left(175^{\circ} \mathrm{C}\right)$. Points a and $\mathrm{b}$ : weight fraction when the solution becomes saturated; $b$ and e: local pressure when the solution becomes saturated; c and f: nucleation onset position [44]. Copyright by Wiley, 2002.

PS [79]. This allowed the injection of sc- $\mathrm{CO}_{2}$ into extruded melt, the mixing of both compounds and the creation of porosity into the extruded polymer. The effects of cooling mode, die temperature and $\mathrm{CO}_{2}$ concentration on material porosity were studied. PS extrudates were manufactured with porosity from 15 to $25 \%$. A rapid cooling was important to solidify the structure. Increasing die temper-
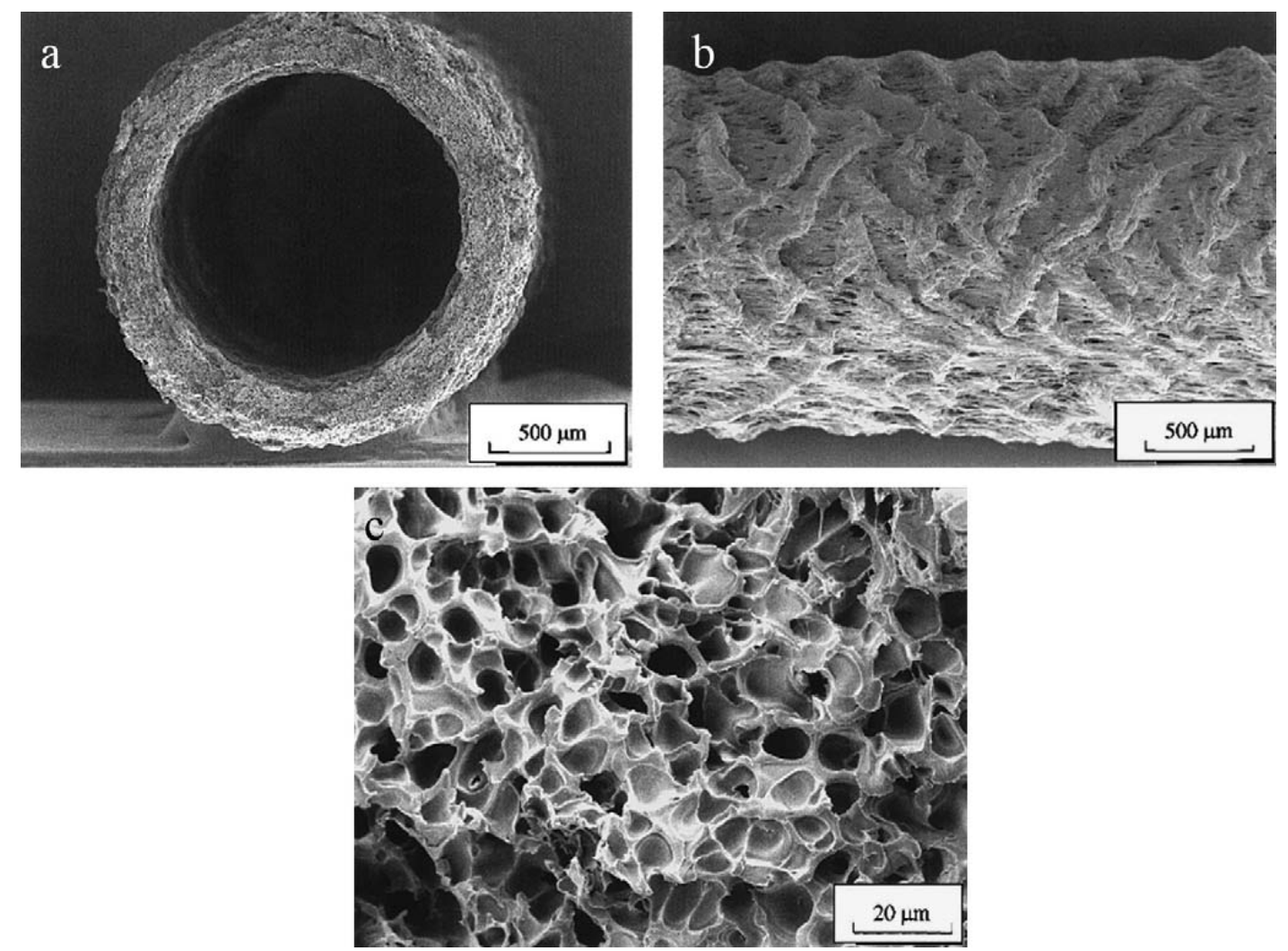

Fig. 11. SEM of a porous PC hollow fibre by extrusion: (a) cross-section, (b) outer surface, (c) cross-section at higher magnification [78]. Copyright by Elsevier, 1999. 
ature enhanced growth and coalescence phenomena, and thus increased total porosity and pore diameter. Finally, this parameter allowed the control of the porosity structure. $\mathrm{CO}_{2}$ concentration showed no significant influence, explained by the fact that part of the injected $\mathrm{CO}_{2}$ remained non-dissolved and was not used to nucleate cells.

The implementation of continuous foaming of poly(vinyl-chloride) (PVC) is scarce. A first study was focused on the design of screw and die to achieve singlephase solution and cell nucleation [80]. Foamed extrudates with thin wall with a thickness of about $0.45 \mathrm{~mm}$ were made, with a density reduction of up to $30 \%$. The cell size obtained was typically much smaller than $100 \mu \mathrm{m}$ with little interconnectivity. In a second study, the authors investigated the effect of PVC formulation on the cell morphology and density of foams [81]. Particular emphasis was placed on understanding the role of acrylic foam-modifier/impact-modifier ratios on fusion, die swelling, cell morphology, and density. Foamed samples of microcellular rigid PVC with a density of approximately $0.15 \mathrm{~g} \mathrm{~cm}^{-3}$ and a tenfold volume expansion were achieved. It was observed that fast fusion of PVC is needed to ensure the formation of a single phase solution. In addition, optimum conditions were found only when the two acrylic-based modifiers were blended. This result implies that the melt must have a viscosity low enough to allow bubble formation and growth, as well as a high enough elasticity to prevent cell coalescence.

Foam production with semicrystalline polymers is less frequent in the literature. In amorphous polymer, the nucleation of cells takes place homogeneously and the polymer expands uniformly. Semicrystalline polymers are two-phase systems in which crystallites are dispersed in the amorphous matrix. As the crystallinity does not favour the solubility and diffusion of $\mathrm{CO}_{2}$ into the polymer, the absorption and diffusion of the $\mathrm{CO}_{2}$ take place almost exclusively through the amorphous regions and the formed polymer/gas solution is not uniform $[82,83]$. Therefore the resulting foam structure is affected by the crystal morphology of the polymer, which is strongly dependent on the processing conditions, in particular the thermal history.

Siripurapu et al. [84] worked on the extrusion with sc$\mathrm{CO}_{2}$ of polyvinylidene fluoride (PVDF). The extrusion of PVDF alone led to low porosity structures which could not be improved appreciably due to the semicrystalline nature of PVDF and its limited sc- $\mathrm{CO}_{2}$ solubility. Although earlier studies suggest that a decrease in foaming temperature of the polymer $/ \mathrm{CO}_{2}$ mixture reduces cell coalescence and promotes high cell nucleation density [43], the reduction of the nozzle temperature results in the generation of PVDF powder. The authors stated that, as the temperature of the PVDF decreases below the melting temperature at which crystals form, the solubility of $\mathrm{CO}_{2}$ decreases, resulting in expulsion of $\mathrm{CO}_{2}$ from the polymer. Due to the presence of impermeable crystals, the internal $\mathrm{CO}_{2}$ pressure induces fracture of the semicrystalline polymer matrix. The authors recommended using this process for coating applications.

In the same work, Siripurapu et al. also extruded PVDF by mixing it with two amorphous polymers having different miscibility with PVDF: PS, highly incompatible, and PMMA, miscible over a broad concentration range [84].
Indeed, physical blending is commonly employed as a means to modify the physical properties of macromolecular systems. Addition of PS reduced the material density, but gave a heterogeneous structure due to residual crystallinity of the PVDF. The presence of two discrete polymer phases during foaming strongly suggests that (i) homogeneous nucleation of the blowing agent occurs as expected in each phase and (ii) heterogeneous nucleation occurs along the PVDF/PS interfaces and PVDF impermeable crystals. On the other hand, with these operating conditions the porous structure of the polymer was greatly improved by adding PMMA. This improvement was explained by higher solubility of $\mathrm{CO}_{2}$ in the mixture (6\% instead of $2 \%$ ), which increased nucleation rate, and thus the uniformity of pores. The addition of PMMA also increased $T_{g}$ of the mixture, which decreased the difference with the process temperature, and thus the available time for growth and coalescence of pores. At lower PVDF concentrations, the PVDF/PMMA blends were homogeneous and entirely amorphous. In consequence, homogeneous nucleation of miscible PVDF/PMMA blends accounted for the most uniform morphologies with small cell diameters. As the PVDF concentration increased, the presence of distinct polymer phases enhances cell coalescence and yields foam morphologies similar to that of the PVDF/PS blend. The influence of the melt and foaming temperatures was also observed for a 40/60 PVDF-PMMA mixture with $6 \%$ of $\mathrm{CO}_{2}$. As previously described by Park et al. (Figs. 7 and 8 [43]), a reduction in melt temperature increased the melt strength and endowed the melt with greater resistance to gas expansion in the cell growth step of the foaming process, and a lower foaming temperature solidified the skin of the foam and reduced the $\mathrm{CO}_{2}$ diffusion from the melt to the atmosphere at the nozzle exit (Fig. 12).

Lee et al. studied extrusion of a 80/20 PE/PS mixture in the presence of $\mathrm{CO}_{2}$ in a twin screw extruder (Leistrizt, LSM diameter $34 \mathrm{~mm}$ ) [85]. A considerable reduction of viscosity was found when $\mathrm{CO}_{2}$ was dissolved in the blend, while also decreasing shear thinning behavior. The cell structures of foamed PE/PS blends showed a dependence of pressure and $\mathrm{CO}_{2}$ concentration, with higher operating pressures and $\mathrm{CO}_{2}$ content leading to a smaller cell size. Finally, it was noted that the size of the dispersed PS phase in the PE/PS phase blends decreased with increasing the $\mathrm{CO}_{2}$ concentration.

Park et al. indicated that microcellular foams cannot be produced from pure low density PE (LDPE) in a conventional microcellular extrusion system because of the high activation energy for cell nucleation [86]. A previous study also showed that the cell population density did not improve significantly with an increase in the talc content in foam processing with high $\mathrm{CO}_{2}$ concentration [87]. To increase the cell-nuclei density, an attempt was made in reducing the free energy for bubble nucleation by heterogeneous cell-nucleation. PS was thus added to induce heterogeneous cell-nucleating spots in LDPE blends with a constant amount of talc as a nucleating agent $[86,88]$. The amount of the PS phase was varied to determine the optimum content. Furthermore, the melt strength of LDPE was increased by using a crosslinking agent. Finally, microcellular LDPE foams have been successfully obtained both with 


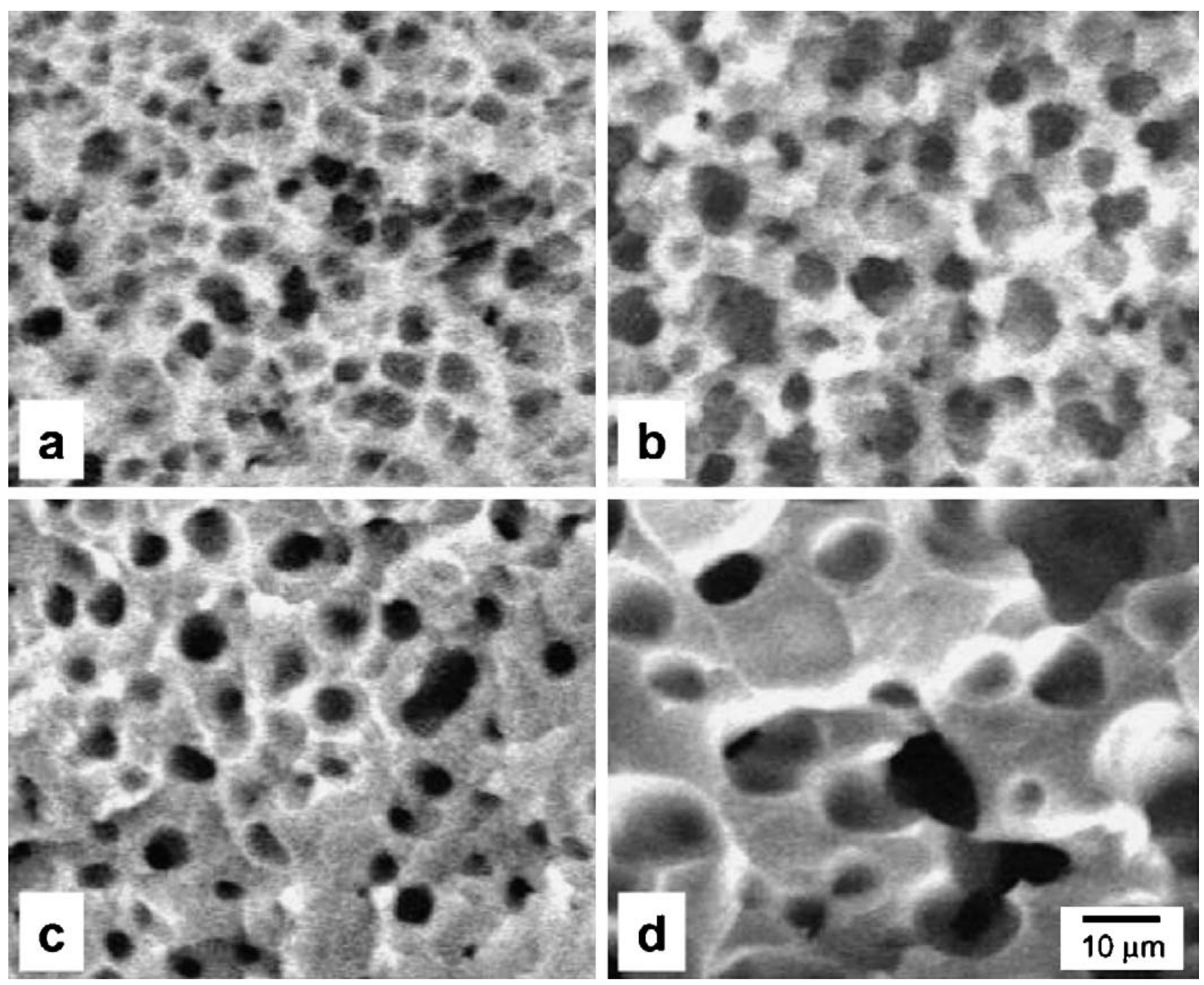

Fig. 12. SEM of 40/60 w/w PVDF/PMMA blends foamed at different temperatures with 6.0 wt $\% \mathrm{sc}^{-\mathrm{CO}}{ }_{2}$ : (a) 140 , (b) 160 , (c) 180 , (d) $200{ }^{\circ} \mathrm{C}$ [84]. Copyright by Elsevier, 2002.

a small amount of PS (5\%) and with crosslinking in the melt. A proper combination of the two increased the cell density steadily.

The same strategy was used to obtain open-cell foams with PP/PE blends [89]. The basic strategy for achieving a high open-cell content is to induce a hard/soft melt structure using two semicrystalline polymers with distinct crystallization temperatures $T_{\mathrm{c}}$, and to foam this inhomogeneous melt structure with supercritical $\mathrm{CO}_{2}$. The effects of polymer blending, die geometry, and temperature on cell opening were investigated in this study. The rate of cell opening increased during the cell growth process when low $-T_{\mathrm{c}}$ polymer domains were well dispersed and embedded in high- $T_{\mathrm{c}}$ polymer matrix. Moreover, higher open cell content was achieved using a die with a high depressurization rate, and working at an optimum processing temperature.

\subsection{Composites: the example of clay-polymer nanocomposites}

Dispersed polymer/clay nanocomposites are of great interest because they can significantly improve the physical, chemical, and mechanical properties of polymeric materials. These improvements may include increased strength, higher modulus, improved thermal stability, enhanced barrier properties, and decreased flammability [90]. However, achieving a high level of clay dispersion has been a key challenge in the production of polymer/clay nanocomposites. Two ideal structures exist for these nanocomposites materials depending on the clay dispersion: intercalated and exfoliated. Intercalation results from the limited insertion of the polymer chains in the clay layer. Conversely, exfoliation is characterized by the insertion of polymer in large quantity and delamination of clay particles, which leads to greater improvement of material properties.

Han et al. investigated the supercritical $\mathrm{CO}_{2}$ extrusion of nanoparticles of clay dispersed in a matrix of PS [91]. The role of these particles is to serve as a nucleation agent and to modify the material properties. During the process, the creation of an exfoliated structure resulted in higher pressure drop caused by higher material viscosity. However the final foam structure was different, having a lower pore size, higher density and smoother surface. This was explained by the better dispersion of clay inside the polymer matrix, which improves the interfacial surface for $\mathrm{CO}_{2}$ absorption and heterogeneous nucleation. The composites also had a higher tensile modulus and better fire retardancy than those of PS foams.

The influence of the concentration of clay particles and pressure drop rate on the intercalated structure obtained 
was studied. The pore sizes decreased with increasing clay concentration and pressure drop, then stabilized at higher values of both parameters. The pore density grew linearly with these two operating parameters.

Therefore, it has to be noted that the use of clay particles allowed the enlargement of the operating range to lower pressures for manufacturing microcellular foams.

Park and co-workers have demonstrated the effect of exfoliated nanoclay on the microcellular foam processing of amorphous and crystalline nylon [92]. It appeared that the nanoclay not only enhanced cell nucleation, but also suppressed cell deterioration during the microcellular foaming of nylon.

A new processing method was developed to help exfoliate and disperse nanoclay into polymer matrices using $\mathrm{sc}-\mathrm{CO}_{2}$. Polypropylene (PP)-layered silicate nanocomposites were prepared by a two-step extrusion process [93]. In the first step, the $\mathrm{PP} /$ clay mixture was extruded with $\mathrm{CO}_{2}$ injected into the barrel of the extruder and the resulting foamed extrudate was cooled and pelletized. In the second step, the foamed material was extruded with venting to produce the final $\mathrm{PP} /$ clay nanocomposites, without $\mathrm{CO}_{2}$. The dispersion properties of clays in the nanocomposites as well as the rheological properties of the nanocomposites were examined. It was found that $\mathrm{sc}-\mathrm{CO}_{2}$ had a measurable effect on the clay dispersion in the polymer matrix and the melt intercalation of a polymer into clay layers.

Treece and Oberhauser investigated two different melt blending strategies for preparing compatible PP-clay nanocomposites, specifically: (1) conventional twin-screw extrusion, and (2) single-screw extrusion following direct sc $-\mathrm{CO}_{2}$ feed to the extruder barrel [94]. The results revealed that the high shear of the twin-screw process was much more successful than the single-screw with in-line $\mathrm{sc}-\mathrm{CO}_{2}$ addition in generating well exfoliated, percolated polypropylene-clay nanocomposites. The authors concluded that the poor results generated by the single-screw extrusion stemmed from two problems. First, the contact time between $\mathrm{sc}-\mathrm{CO}_{2}$ and clay might be too short to allow significant diffusion into the clay inter-gallery spaces. Second, thermodynamics limited the amount of $\mathrm{CO}_{2}$ that polypropylene could solubilize, and that quantity might be insufficient to swell clay intergalleries during processing. As a result, they concluded that pre-treating clay with $\mathrm{sc}-\mathrm{CO}_{2}$ in pressurized vessels prior to extrusion might better promote clay exfoliation and dispersion.

$\mathrm{PP} /$ clay composite with improved mechanical properties were prepared by a process involving pre-treating the clay [95]. This was linked to the direct contact of the clay with sc- $\mathrm{CO}_{2}$, rapid expansion and injection of the mixture into the extruder where it was dispersed into the polymer melt. More exfoliated clay particles were made and it resulted in better mechanical properties of a polypropylene/clay composite (Fig. 13). It was hypothesized that $\mathrm{CO}_{2}$ readily entered the galleries of the nanoclay (treated with alkyl quaternary ammonium salts) and swelled the alkyl chains. When the pressure was partially released, $\mathrm{CO}_{2}$ expanded the galleries and, thereby, further exfoliated the clay particles.
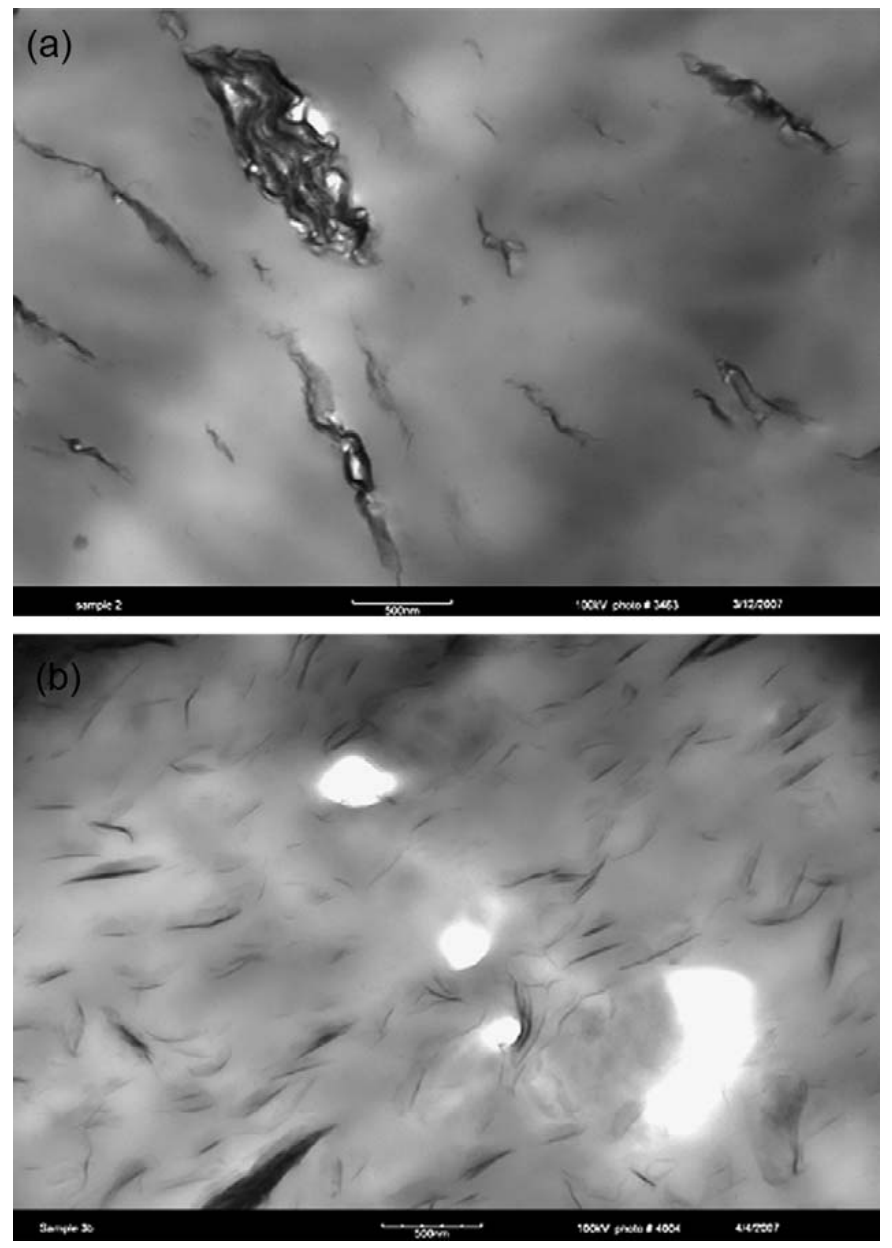

Fig. 13. Micrographs of composites prepared with injection of the $\mathrm{CO}_{2}$ : (a) alone, (b) previously mixed with the nanoparticles [95]. Copyright by Elsevier, 2007.

\subsection{Biopolymers and pharmaceutical applications}

Polymers are widely used in several areas. However, due to their slow degradability and the predicted exhaustion of the world petroleum reserves, significant environmental problems have arisen. Therefore, it is necessary to replace them with bioplastics that degrade much quicker when exposed to a biologically active environment.

Extrusion, called "hot-melt extrusion" in pharmaceutical technology, represents an efficient manufacturing technology to disperse up to a molecular level a pharmaceutical ingredient into a polymeric matrix [3]. Most of the applications describe the preparation of solid dispersions either to increase the aqueous solubility and oral bioavailability of the active substance or to control its release. However, one of the major drawbacks of extrusion is that it can only be applied to process thermally stable molecules. For a number of drugs, proteins and other excipients, extrusion cannot be used unless a plasticizer is added to reduce the viscosity of the mixture, permitting reduction of the processing temperature in the extruder. However, these additives remain in the product and thus alter its properties and performance. In this context, combining extrusion with sc- $\mathrm{CO}_{2}$ facilitates the use of fragile or thermally sensitive molecules, like pharmaceuticals, with- 

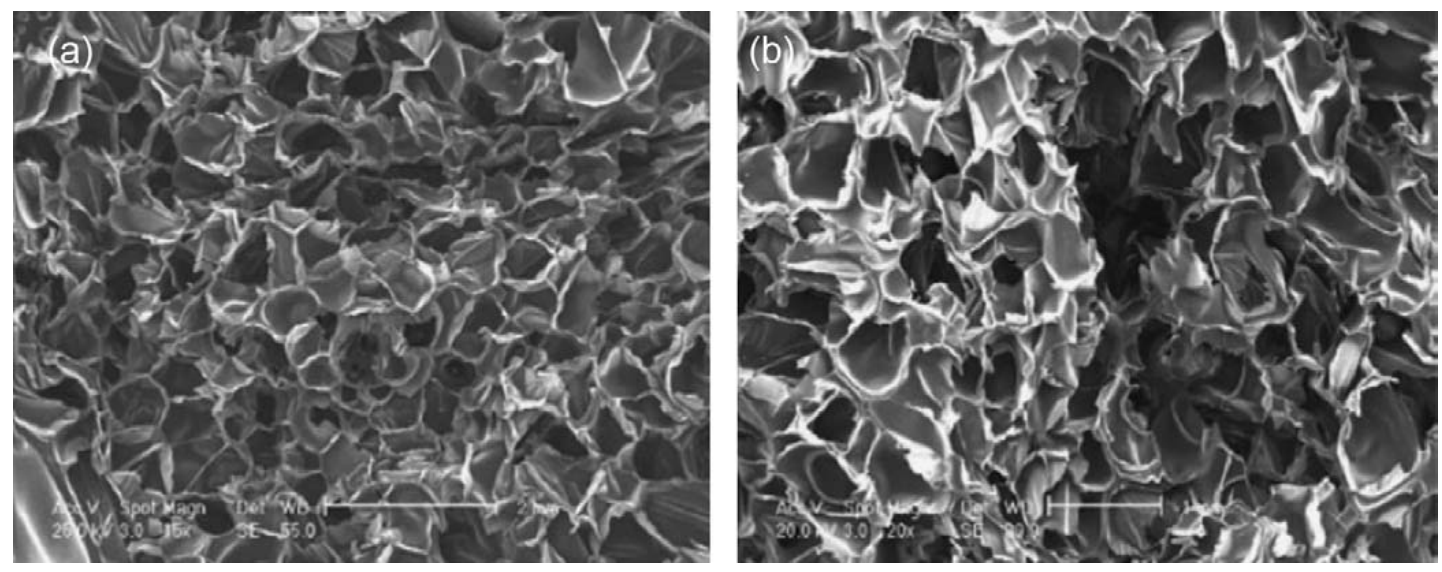

Fig. 14. SEM of Eudragit foams [37].

out any residue in the final product. Moreover, in tissue engineering, the technique offers the interesting possibility of building biodegradable scaffolds, which would allow new cell colonization and tissue regeneration [96,97].

Nikitine et al. [37,38] studied the correlation between operating conditions and foam structures of a pharmaceutical grade acrylic polymer, Eudragit ${ }^{\circledR}$ E100 (Fig. 14). The effect of three operating parameters was studied: the temperature fixed at the same value in the die and in the metering zone, the screw speed and the volumetric flow rate of $\mathrm{CO}_{2}$. Screw speed had no significant effect on the structure of the material. On the contrary, temperature appeared to be the most significant parameter. An increase in temperature favoured the growth phenomenon and consequently the expansion rate and the average pore diameter. Moreover, coalescence phenomenon appeared at high temperature and extrudates were more heterogeneous. Finally, the effect of low concentrations of $\mathrm{CO}_{2}$ was demonstrated. Indeed, when the quantity of $\mathrm{CO}_{2}$ increased the $\mathrm{CO}_{2}$-polymer blend was not in a single-phase state. This was apparently due to the mixing time being longer than the residence time. Logically, increasing the $\mathrm{CO}_{2}$ concentration increased the expansion rate and the average cell diameter. Later, a fast dissolving formulation of Carvedilol, a poorly water soluble drug against hypertension, was produced by the same process using the Eudragit ${ }^{\circledR}$ E100 as a porous polymer matrix [98].

This work was also completed by the study of the influence of $\mathrm{sc}-\mathrm{CO}_{2}$ on the polymer flow in the extruder $[37,39]$. For this, the authors investigated the residence time distribution (RTD) of a dye with and without injection of $\mathrm{sc}-\mathrm{CO}_{2}$. A non-ideal behavior of the flow was observed, with the presence of stagnant zones. Moreover, as a consequence of the decrease of polymer viscosity, the first dye particles appeared earlier when $\mathrm{CO}_{2}$ was injected.

Experimental RTD were represented with and without injection of $\mathrm{sc}-\mathrm{CO}_{2}$. The model used was a cascade of Continuous Stirred Tank Reactor (CSTR) with stagnant zones followed by a plug flow reactor. It appeared that the presence of $\mathrm{CO}_{2}$ tended to favour exchange between the principal flow and the stagnant zones [39]. A model based on the Markov chain theory was also developed in another study [99]. In this model, the whole free volume of the extruder is divided into several cells, which represent the finite volumes between the screw and barrel wall. The relationships between the cells are only determined by the probabilities of transitions of a part of mass in a cell that transits to an adjacent cell. The evolution of the system was calculated after each transition to finally obtain a discrete outflow. Finally, this model allows calculating the response to any test signal, taking into account different velocity profiles.

More recently, the same team has obtained foams with porosity up to $70 \%$ with a polyhydroxybutyratehydroxyvalerate (PHB-HV), a semi-crystalline polymer synthesized by microorganisms as energy reserve materials in the presence of an excess carbon source [40].

Verreck et al. presented results obtained with an intermeshing co-rotating twin screw extruder (Leistrizt, micro $\emptyset 18$ ). They showed that pressurized carbon dioxide worked as a reversible plasticizer and foaming agent for several pharmaceutically acceptable polymers, including polyvinylpyrrolidone-co-vinyl acetate 64 (PVP-VA 64), Eudragit ${ }^{\circledR}$ E100 and ethylcellulose 20 cps (EC 20 cps) [59]. They then studied the possibilities of combining pressurized carbon dioxide with hot stage extrusion during manufacturing of solid dispersions of itraconazole with PVP-VA 64 [60] and EC 20 cps [61]. Carbon dioxide acted as a plasticizer for the two mixtures with itraconazole, reducing the processing temperature during the hot stage extrusion process. The macroscopic morphology changed to a foamlike structure due to expansion of the carbon dioxide at the extrusion die (Fig. 15). This resulted in increased specific surface area, porosity, hygroscopicity and improved milling efficiency. Other experiments on p-amino salicylic acid with EC20 clearly showed that injecting pressurized $\mathrm{CO}_{2}$ broadens the application of hot stage extrusion to thermally labile compounds [62].

Lyons et al. used sc- $\mathrm{CO}_{2}$ as a plasticizer in the hot melt production of a range of polymer matrices for sustained oral drug delivery [100]. Several batches of matrix material, composed of polyethylene oxide (PEO) and Eudragit EPO, were prepared incorporating an API, Carvedilol. They were then processed both with and without sc- $\mathrm{CO}_{2}$ incorpora- 

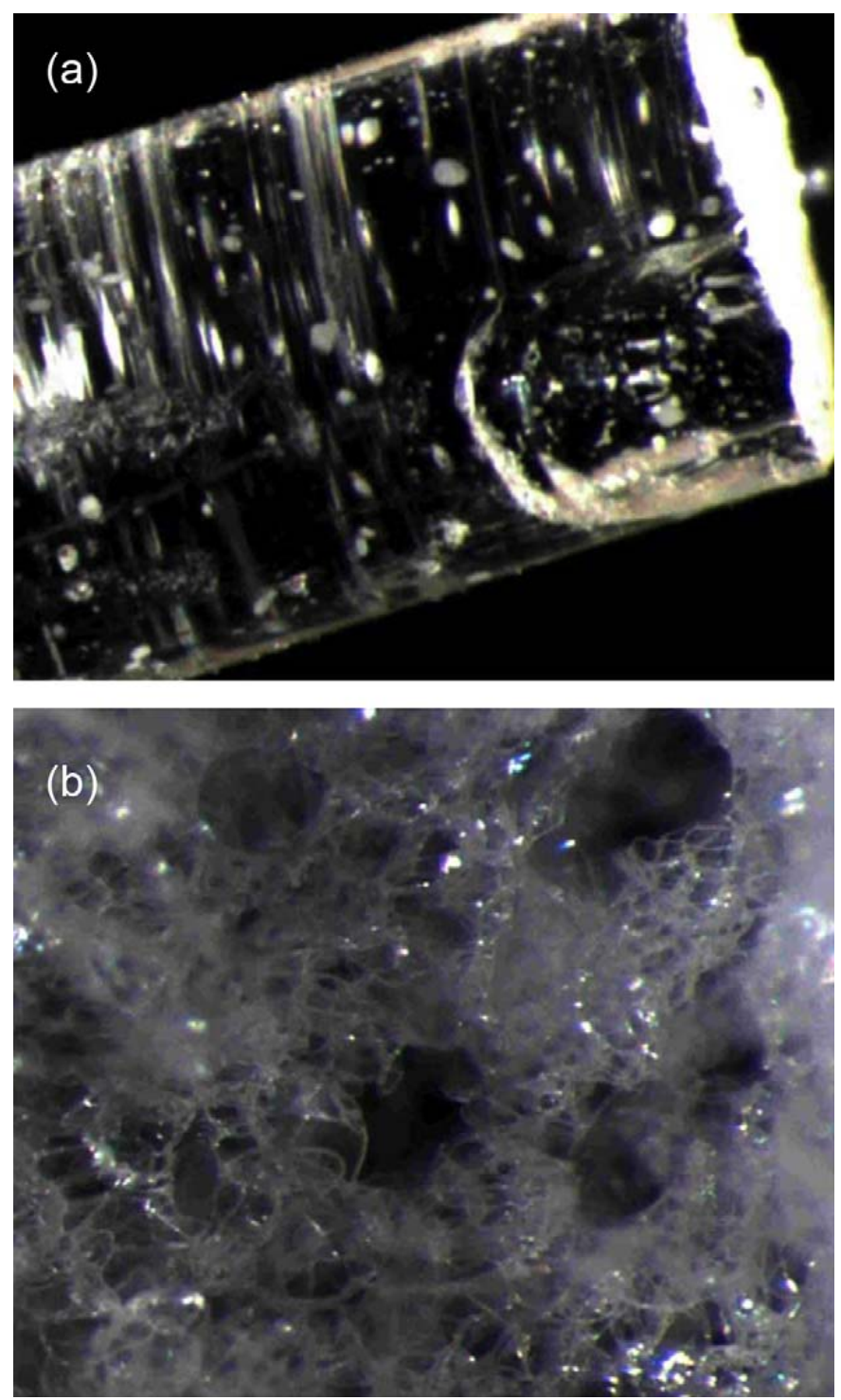

Fig. 15. Hot stage extrusion of itraconazole/PVP-VA 64: (a) with and (b) without $\mathrm{CO}_{2}$ injection [60]. Copyright by Elsevier, 2005.

tion. Characterization of the resultant matrices revealed that the placticizing effect occurred only in the barrel of the extruder and that no viscosity reduction was observed after processing. The incorporation of $\mathrm{sc}-\mathrm{CO}_{2}$ led to a higher propensity for crystallization in PEO. Dissolution analysis showed that the use of $\mathrm{sc}-\mathrm{CO}_{2}$ during the extrusion process resulted in a faster dissolution of API when compared with unassisted extrusion.

Extrusion foaming of amorphous poly lactic acid (PLA) using carbon dioxide $\left(\mathrm{CO}_{2}\right)$ as the blowing agent was also investigated. Detailed results describing the plasticization induced by $\mathrm{CO}_{2}$ dissolution as measured from two different methods, on-line rheometry and in-line ultrasonic technique were given [101]. Finally, extrusion of PLA foams in the $20-25 \mathrm{~kg} \mathrm{~m}^{-3}$ density range was achieved. However, the associated processing window was very narrow: $\mathrm{CO}_{2}$ content lower than $7 \mathrm{wt} \%$ did not lead to significant foam expansion while foams blown at $\mathrm{CO}_{2}$ contents larger than $8.3 \mathrm{wt} \%$ showed severe shrinkage upon ageing. Talc affected the cell morphology of PLA foams at lower $\mathrm{CO}_{2}$ concentration (below approximately $5 \mathrm{wt} \%$ ) because its addition in the matrix led to foams with much finer cells and a higher cell density. Thus, observation indicates that talc particles act as heterogeneous nucleating sites for cell nucleation. Nevertheless, the effect of talc disappeared at higher $\mathrm{CO}_{2}$ contents.

Mihai et al. have also obtained low density open-cell foams from PLA [102]. $\mathrm{CO}_{2}$ was found to be a highly soluble blowing agent for PLA, but as previously observed, low density PLA foams were obtained only when the $\mathrm{CO}_{2}$ concentration exceeded $7 \mathrm{wt} \%$. The PLA foam morphology was characterized by fine cells and high open-cell content associated with cell wall rupture during the rapid $\mathrm{CO}_{2}$ foam cell expansion. Moreover, it was observed that significant crystallinity was developed during the foaming process, due to the high $\mathrm{CO}_{2}$ concentration which induced more chain mobility. The use of $0.5 \mathrm{wt} \%$ talc as a foam and crystalline nucleating agent did not modify the foam structure or the crystalline level obtained. The authors have also studied three different grades of PLA that differed in terms of L-lactic acid content [103]. The crystallinity developed on expansion depended on the L-lactic acid content, supercritical $\mathrm{CO}_{2}$ concentration, polymer flow rate, and die diameter. This crystallinity development in PLA enhanced its cellular structure formation and enabled the fabrication of quality cellular materials at lower $\mathrm{CO}_{2}$ concentration. A close examination of the ruptured cells in highly crystalline foams led to the discovery of finely "pockmarked" cell walls. The authors stated that this peculiar 2D-cavitation phenomena shows that PLA crystallites are present during the foam nucleation state.

Lee et al. compared foaming of PLA with chemical and physical blowing agents. The CBA, Azodicarbonamide, provided nitrogen upon decomposition, while $\mathrm{CO}_{2}$ was used as PBA [104]. At 5\% $\mathrm{CO}_{2}$, cell density increased with decreasing die temperature. For higher die temperatures, this led to reduction of the extrudate density, but at lower die temperatures, foam density increased, probably due to too high a melt strength. The chemical blowing agent showed less foaming efficiency because of a lower solubility in the polymer.

Lately, Matuana and Diaz [105] focused on the understanding of the nucleation mechanisms in PLA in order to generate microcellular structures in a continuous extrusion process. Finally, microcellular morphology was successfully produced, irrespective of the PLA type (amorphous or semicrystalline). Moreover, the presence of nanoclays did not affect the homogeneous nucleation but increased the heterogeneous nucleation, resulting in a bicellular structure, as previously observed for PVC [81]. The authors stated that this may be indicative of two nucleation stages, cells nucleated earlier (homogeneous) having a longer time for growth than cells nucleated later (heterogeneous) leading to cells of smaller size.

Blends of PLA with thermoplastic starch could be foamed to low density values but interfacial modification using maleated PLA was necessary [102]. An open-cell structure was also present when foaming these blends, however with a modified ruptured cell structure. 


\section{Conclusion: assisting extrusion process by supercritical $\mathrm{CO}_{2}$ extends the field of application and opens new opportunities}

The coupling of extrusion and supercritical $\mathrm{CO}_{2}$ technologies has broadened the field of application of extrusion processes.

The first applications of sc- $\mathrm{CO}_{2}$-assisted extrusion were developed for the agro-food industry 20 years ago. However, most thermoplastics are potential candidates for sc- $\mathrm{CO}_{2}$-assisted extrusion.

The nucleation, growth and coalescence phenomena, and consequently the expansion rate, the average pore diameter and density, are driven by the following operating parameters: the temperature of the material before the pressure drop, the die temperature, the screw speed and the $\mathrm{CO}_{2}$ content. Tuning the operating conditions can thus control the structure of polymeric foams.

This coupled technology is however still new and further developments of both experimental and modelling studies are necessary to allow better theoretical understanding and process control prior to industrial use.

New challenging opportunities are expected in the field of pharmaceutical applications, like the possibility of mastering microcellular foam manufacture for making solid dispersions of a drug with controlled release. In tissue engineering the possibility of making biodegradable scaffolds allowing new cell colonization and tissue regeneration is also very promising.

\section{References}

[1] Rauwendaal C. Polymer extrusion. München: Hanser Publishers; 2001.

[2] Sharma SK, Mulvaney S, Rizvi SSH. Food process engineering: theory and laboratory experiments. New York: John Wiley; 2000.

[3] Breitenbach J. Melt extrusion: from process to drug delivery technology. Eur J Pharm Biopharm 2002;54:107-17.

[4] Lee ST. Foam extrusion: principles and practice. Boca Raton: CRC Press; 2000.

[5] Tomasko DL, Burley A, Feng L, Yeh SK, Miyazono K, Nirmal-Kumar $\mathrm{S}$, Kusaka I, Koelling K. Development of $\mathrm{CO}_{2}$ for polymer foam applications. J Supercrit Fluids 2009;47:493-9.

[6] Eckert C, Knutson B, Debenedetti P. Supercritical fluids as solvents for chemical and materials processing. Nature 1996:383:313-83.

[7] Nalawade SP, Picchioni F, Janssen LPBM. Supercritical carbon dioxide as a green solvent for processing polymer melts: processing aspects and applications. Prog Polym Sci 2006;31:19-43.

[8] Cooper AI. Synthesis and processing of polymers using supercritical carbon dioxide. J Mater Chem 2000;10:207-34.

[9] Tomasko DL, Li HB, Liu DH, Han XM, Wingert MJ, Lee LJ, Koelling KW. A review of $\mathrm{CO}_{2}$ applications in the processing of polymers. Ind Eng Chem Res 2003;42:6431-56.

[10] Kazarian SC. Polymer processing with supercritical fluids. Polym Sci 2000;42:78-101.

[11] Sato Y, Fujiwara K, Takikawa T, Takishima S, Masuoka H. Solubilities and diffusion coefficients of carbon dioxide and nitrogen in polypropylene, high-density polyethylene, and polystyrene under high pressures and temperatures. Fluid Phase Equilib 1999;162:261-76.

[12] Gourgouillon D, Avelino HMNT, Fareleira JMNA, Nunes Da Ponte M. Simultaneous viscosity and density measurement of supercritical $\mathrm{CO}_{2}$-saturated PEG 400. J Supercrit Fluids 1998;13:177-85.

[13] Kwag C, Manke CW, Gulari E. Rheology of molten polystyrene with dissolved supercritical and near-critical gases. J Polym Sci B Polym Phys 1999;37:2771-81.

[14] Wang WCV, Kramer EJ, Sachse WH. Effects of high-pressure $\mathrm{CO}_{2}$ on the glass transition temperature and mechanical properties of polystyrene. J Polym Sci B Polym Phys 1982;20:1371-84.
[15] Condo PD, Sanchez IC, Panayiotou CG, Johnston KP. Glass transition behavior including retrograde vitrification of polymers with compressed fluid diluents. Macromolecules 1992;25: 6119-27.

[16] Royer J, Gay Y, Adam M, DeSimone J, Khan S. Polymer melt rheology with high pressure $\mathrm{CO}_{2}$ using a novel magnetically levitated sphere rheometer. Polymer 2002;43:2375-83.

[17] Areerat S, Nagata T, Ohshima M. Measurement and prediction of $\mathrm{LDPE} / \mathrm{CO}_{2}$ solution viscosity. Polym Eng Sci 2002;42:2234-45.

[18] Lee M, Tzoganakis C, Park CB. Effects of supercritical $\mathrm{CO}_{2}$ on the viscosity and morphology of polymer blends. Adv Polym Technol 2000;19:300-11.

[19] Cho KY, Rizvi SSH. 3D microstructure of supercritical fluid extrudates. I. Melt rheology and microstructure formation. Food Res Int 2009;42:595-602.

[20] Li H, Lee LJ, Tomasko DL. Effect of carbon dioxide on the interfacial tension of polymer melts. Ind Eng Chem Res 2004;43:509-14.

[21] Jaeger PT, Eggers R, Baumgartl $\mathrm{H}$. Interfacial properties of high viscous liquids in a supercritical carbon dioxide atmosphere. $\mathrm{J}$ Supercrit Fluids 2002;24:203-17.

[22] Jacobs LJM, Kemmere MF, Keurentjes JTF. Sustainable polymer foaming using high pressure carbon dioxide: a review on fundamentals, processes and applications. Green Chem 2008;10: 731-8.

[23] Walker TA, Frankowski DJ, Spontak RJ. Thermodynamics and kinetic processes of polymer blends and block copolymers in the presence of pressurized carbon dioxide. Adv Mater 2008;20:879-98

[24] Gendron R, Champagne MF, Reignier J. Supercritical fluids in thermoplastics foaming: facts or fallacies? Cell Polym 2006:25:199-220.

[25] Rizvi SSH, Mulvaney SJ. Extrusion processing with supercritical fluids. US Patent 5120559 (1992).

[26] Alavi SH, Gogoi BK, Kahn M, Bowman BJ, Rizvi SSH. Structural properties of protein-stabilized starch-based supercritical fluid extrudates. Food Res Intern 1999;32:107-18.

[27] Goel SK, Beckman EJ. Generation of microcellular polymers using supercritical $\mathrm{CO}_{2}$. Cell Polym 1993;12:251-73.

[28] Goel SK, Beckman EJ. Generation of microcellular polymeric foams using supercritical carbon dioxide. I. Effect of pressure and temperature on nucleation. Polym Eng Sci 1994;34:1137-47.

[29] Han X, Koelling KW, Tomasko DL, Lee LJ. Effect of die temperature on the morphology of microcellular foams. Polym Eng Sci 2003;43:1206-20.

[30] Colton JS, Suh NP. The nucleation of microcellular thermoplastic foam with additives. 1. Theoretical considerations. Polym Eng Sci 1987;27:485-92.

[31] Colton JS, Suh NP. The nucleation of microcellular thermoplastic foam with additives. 2. Experimental results and discussion. Polym Eng Sci 1987;27:493-9.

[32] Kichatov BV, Korshunov AM. Nucleation of gas bubbles in extrusion foaming of high-pressure polyethylene. Theor Found Chem Eng 2005;39:643-52.

[33] Marchal T. Challenges of modelling the extrusion process. Plast Rubber Compos 2005;34:265-70.

[34] Shukla S, Koelling KW. Classical nucleation theory applied to homogeneous bubble nucleation in the continuous microcellular foaming of the polystyrene- $\mathrm{CO}_{2}$ system. Ind Eng Chem Res 2009;48:7603-15.

[35] Taki K, Nakayama T, Yatsuzuka T, Ohshima M. Visual observations of batch and continuous foaming processes. J Cell Plast 2003;39:155-69.

[36] Han JH, Han CD. A study of bubble nucleation in a mixture of molten polymer and volatile liquid in a shear flow field. Polym Eng Sci 1988;28:1616-27.

[37] Nikitine C. Elaboration d'un matériau poreux d'Eudragit E100 par extrusion assistée par $\mathrm{CO}_{2}$ supercritique: de la conception à la compréhension du procédé. Thèse de doctorat, Ecole des Mines de Paris, SMI-Spécialité Génie des Procédés, 2007.

[38] Nikitine C, Rodier E, Sauceau M, Letourneau JJ, Fages J. Controlling the structure of a porous polymer by coupling supercritical $\mathrm{CO}_{2}$ and single screw extrusion process. J Appl Polym Sci 2010;115:981-90.

[39] Nikitine C, Rodier E, Sauceau M, Fages J. Residence time distributions of a pharmaceutical grade polymer melt in a single screw extrusion process. Chem Eng Res Design 2009;87:809-16.

[40] Kamar K, Sauceau M, Rodier E, Fages J. Biopolymer foam production using a $\left(\mathrm{SC} \mathrm{CO}_{2}\right)$-assisted extrusion process. In: Cansell F, Fages J, Mercadier J, editors. Proceedings of the 9th international symposium on supercritical fluids. 2009. P099/1-6. 
[41] Span R, Wagner W. A new equation of state for carbon dioxide covering the fluid region from the triple-point temperature to $1100 \mathrm{~K}$ at pressures up to $800 \mathrm{MPa}$. J Phys Chem Ref Data 1996;25: 1509-96.

[42] Peng D-Y, Robinson D. A new two-constant equation of state. Ind Eng Chem Fundam 1976;15:59-64.

[43] Park CB, Behravesh AH, Venter RD. Low density microcellular foam processing in extrusion using $\mathrm{CO}_{2}$. Polym Eng Sci 1998;38:1812-23.

[44] Han X, Koelling KW, Tomasko DL, Lee LJ. Continuous microcellular polystyrene foam extrusion with supercritical $\mathrm{CO}_{2}$. Polym Eng Sci 2002;42:2094-106.

[45] Mulvaney SJ, Rizvi SSH. Extrusion processing with supercritical fluids. Food Technol 1993;47:74-82.

[46] Rizvi SSH, Mulvaney SJ. Supercritical fluid extrusion process and apparatus. US Patent 5417992 (1995).

[47] Rizvi SSH, Mulvaney SJ, Sokhey AS. The combined application of supercritical fluid and extrusion technology. Trends Food Sci Technol 1995;6:232-40.

[48] Sokhey AS, Rizvi SSH, Mulvaney SJ. Application of supercritical fluid extrusion to cereal processing. Cereal Foods World 1996;41:29-34.

[49] Chen K-H, Dogan E, Rizvi SSH. Supercritical fluid extrusion of masabased snack chips. Cereal Foods World 2002;47:44-51.

[50] Singh B, Rizvi SSH. Residence time distribution (RTD) and goodness of mixing (GM) during $\mathrm{CO}_{2}$-injection in twin-screw extrusion. Part I: RTD studies. J Food Process Eng 1998;21:91-110.

[51] Singh B, Rizvi SSH. Residence time distribution (RTD) and goodness of mixing (GM) during $\mathrm{CO}_{2}$-injection in twin-screw extrusion. Part II: GM studies. J Food Process Eng 1998;21:111-26.

[52] Gogoi BK, Alavi SH, Rizvi SSH. Mechanical properties of proteinstabilized starch-based supercritical fluid extrudates. Int J Food Prop 2000;3:37-58.

[53] Hicsasmaz Z, Dogan E, Chu C, Rizvi SSH. Leavened dough processing by supercritical fluid extrusion (SCFX). J Agric Food Chem 2003;51:6191-7.

[54] Chen K-H, Rizvi SSH. Rheology and expansion of starch-water- $\mathrm{CO}_{2}$ mixtures with controlled gelatinization by supercritical fluid extrusion. Int J Food Prop 2006;9:863-76.

[55] Ayoub A, Rizvi SSH. Properties of supercritical fluid extrusion-based crosslinked starch extrudates. J Appl Polym Sci 2008;107:3663-71

[56] Mariam I, Cho KY, Rizvi SSH. Thermal properties of starch-based biodegradable foams produced using supercritical fluid extrusion (SCFX). Int J Food Prop 2008;11:415-26.

[57] Alavi S, Rizvi SSH. Strategies for enhancing expansion in starch-based microcellular foams produced by supercritical fluid extrusion. Int J Food Prop 2005;8:23-34.

[58] Cho KY, Rizvi SSH. The time-delayed expansion profile of supercritical fluid extrudates. Food Res Int 2008;41:31-42.

[59] Verreck G, Decorte A, Tomasko D, Arien A, Peeters J, Rombaut P, Van den Mooter G, Brewster ME. The effect of pressurized carbon dioxide as a plasticizer and foaming agent on the hot melt extrusion process and extrudate properties of pharmaceutical polymers. J Supercrit Fluids 2006;38:383-91.

[60] Verreck G, Decorte A, Heymans K, Adriaensen J, Cleeren D, Jacobs A, Liu D, Tomasko D, Arien A, Peeters J, Rombaut P, Van den Mooter $\mathrm{G}$, Brewster ME. The effect of pressurized carbon dioxide as a temporary plasticizer and foaming agent on the hot stage extrusion process and extrudate properties of solid dispersions of itraconazole with PVP-VA 64. Eur J Pharm Sci 2005;26:349-58.

[61] Verreck G, Decorte A, Heymans K, Adriaensen J, Liu D, Tomasko D, Arien A, Peeters J, Rombaut P, Van den Mooter G, Brewster ME. The effect of supercritical $\mathrm{CO}_{2}$ as a reversible plasticizer and foaming agent on the hot stage extrusion of itraconazole with EC $20 \mathrm{cps}$. J Supercrit Fluids 2007;40:153-62.

[62] Verreck G, Decorte A, Heymans K, Adriaensen J, Liu D, Tomasko D, Arien A, Peeters J, Van den Mooter G, Brewster ME. Hot stage extrusion of p-amino salicylic acid with EC using $\mathrm{CO}_{2}$ as a temporary plasticizer. Int J Pharm 2006;327:45-50.

[63] Benkreira H, Gale M, Patel R, Cox M, Paragreen J. Novel extrusion dies with rotating rollers for $\mathrm{CO}_{2}$-plastic foam production. Int Polym Process 2004;19:111-7.

[64] Gendron R, Champagne MF, Delaviz Y, Polasky ME. Foaming polystyrene with a mixture of $\mathrm{CO}_{2}$ and ethanol. J Cell Plast 2006;42:127-38.

[65] Champagne MF, Gendron R, Vachon C, Rampalli S. Foaming polyethylene with $\mathrm{CO}_{2}$-based mixtures of blowing agents. ANTEC conference proceedings, vol. 3. 2004. p. 3125-9.

[66] Ferdinand JM, Lai-Fook RA, Ollet AL, Smith AC, Clark SA. Structure by carbon dioxide injection in extrusion cooking. J Food Eng 1990;11:209-24.
[67] Levenspiel O. Chemical reaction engineering. 2nd ed. New York: John Wiley \& Sons; 1972.

[68] Lee PC, Kaewmesri W, Wang J, Park CB, Pumchusak J, Folland $\mathrm{R}$, Praller A. Effect of die geometry on foaming behaviors of high-melt-strength polypropylene with $\mathrm{CO}_{2}$. J Appl Polym Sci 2008;109:3122-32.

[69] Xu X, Park CB. Effects of the die geometry on the expansion of polystyrene foams blown with carbon dioxide. J Appl Polym Sci 2008;109:3329-36.

[70] Jeong HS, Toledo RT. Twin-screw extrusion at low temperature with carbon dioxide injection to assist expansion: extrudate characteristics. J Food Eng 2004;63:425-32.

[71] Park CB, Suh NP, Baldwin DF. Method for providing continuous processing of microcellular and supermicrocellular foamed materials. US Patent 5866053 (1999).

[72] Lee PC, Li GM, Lee JWS, Park CB. Improvement of cell opening by maintaining a high temperature difference in the surface and core of a foam extrudate. J Cell Plast 2007;43:431-44.

[73] Lee JWS, Wang KY, Park CB. Challenge to extrusion of low-density microcellular polycarbonate foams using supercritical carbon dioxide. Ind Eng Chem Res 2005;44:92-9.

[74] Shukla S, Koelling KW. Steady flow simulation of a polymer-diluent solution through an abrupt axisymmetric contraction using internally consistent rheological scaling. J Appl Polym Sci 2007; 106:1053-74

[75] Sanchez IC, Lacombe RH. An elementary molecular theory of classical fluids - pure fluid. J Phys Chem 1976;80:2352-62.

[76] Sanchez IC, Lacombe RH. Statistical thermodynamics of polymer solutions. Macromolecules 1978;11:1145-56.

[77] Kikic I. Polymer-supercritical fluid interactions. J Supercrit Fluids 2009;47:458-65.

[78] Huang Q, Seibig B, Paul D. Polycarbonate hollow fiber membranes by melt extrusion. J Membr Sci 1999;161:287-91.

[79] Sauceau M, Nikitine C, Rodier E, Fages J. Effect of supercritical carbon dioxide on polystyrene extrusion. J Supercrit Fluids 2007;43:367-73.

[80] Vanvuchelen J, Perugini C, Deweerdt M, Chen L, Burnham T. Microcellular PVC foam for thin wall profile. J Cell Plast 2000;36:148-57.

[81] Diaz CA, Matuana LM. Continuous extrusion production of microcellular rigid PVC. J Vinyl Addit Technol 2009;15:211-8.

[82] Doroudiani S, Park CB, Kortschot MT. Effect of the crystallinity and morphology on the microcellular foam structure of semicrystallines polymer. Polym Eng Sci 1996;36:2645-62.

[83] Doroudiani S, Park CB, Kortschot MT. Processing and characterization of microcellular foamed high-density polyethylene/isotactic polypropylene blends. Polym Eng Sci 1998;38:1205-15.

[84] Siripurapu S, Gay Y, Royer J, Adam M, DeSimone J, Spontak R, Khan S. Generation of microcellular foams of PVDF and its blends using supercritical carbon dioxide in a continuous process. Polymer 2002;43:5511-20.

[85] Lee M, Tzoganakis C, Park CB. Extrusion of PE/PS blends with supercritical carbon dioxide. Polym Eng Sci 1998;38:1112-20.

[86] Park CB, Lee PC, Wang J, Padareva V. Strategies for achieving microcellular LDPE foams in extrusion. Cell Polym 2006;25:1-18.

[87] Park CB, Cheung LK, Song SW. The effect of talc on cell nucleation in extrusion foam processing of polypropylene with $\mathrm{CO}_{2}$ and isopentane. Cell Polym 1998; 17:221-51.

[88] Lee PC, Wang J, Park CB. Extrusion of microcellular open-cell LDPEbased sheet foams. J Appl Polym Sci 2006;102:3376-84.

[89] Lee PC, Wang J, Park CB. Extruded open-cell foams using two semicrystalline polymers with different crystallization temperatures. Ind Eng Chem Res 2006;45:175-81.

[90] Lee LJ, Zeng CC, Cao X, Han XM, Shen J, Xu GJ. Polymer nanocomposite foams. Compos Sci Technol 2005;65:2344-63.

[91] Han X, Zeng C, Lee LJ, Koelling KW, Tomasko DL. Extrusion of polystyrene nanocomposite foams with supercritical $\mathrm{CO}_{2}$. Polym Eng Sci 2003;43:1261-75.

[92] Zheng WG, Lee YH, Park CB. The effects of exfoliated nano-clay on the extrusion microcellular foaming of amorphous and crystalline nylon. J Cell Plast 2006;42:271-88.

[93] Lee SM, Shim DC, Lee JW. Rheology of PP/clay hybrid produced by supercritical $\mathrm{CO}_{2}$ assisted extrusion. Macromol Res 2008;16:6-14.

[94] Treece MA, Oberhauser JP. Processing of polypropylene-clay nanocomposites: single-screw extrusion with in-line supercritical carbon dioxide feed versus twin-screw extrusion. J Appl Polym Sci 2007; 103:884-92.

[95] Nguyen QT, Baird DG. An improved technique for exfoliating and dispersing nanoclay particles into polymer matrices using supercritical carbon dioxide. Polymer 2007;48:6923-33. 
[96] Hentze HP, Antonietti M. Porous polymers and resins for biotechnological and biomedical applications. Rev Mol Biotechnol 2002;90:27-53.

[97] Duarte ARC, Mano JF, Reis RL. Perspectives on: supercritical fluid technology for 3D tissue engineering scaffold applications. J Bioact Compat Polym 2009;24:385-400.

[98] Nagy ZK, Sauceau M, Marosi G, Rodier E, Fages J. Control of the dissolution rate of an active pharmaceutical ingredient by using melt extrusion coupled with supercritical $\mathrm{CO}_{2}$. In: Gamse T, Fages J, Perrut M, editors. Proceedings 12th European Meeting on Supercritical Fluids. 2010. p. CO72.

[99] Ponomarev D, Sauceau M, Nikitine C, Rodier E, Fages J. Application of the Markov chain theory for modelling residence time distribution in a single screw extruder. In: Veciana J, Vega L, Ventosa $\mathrm{N}$, editors. Proceedings 11th European Meeting on Supercritical Fluids. 2008. P_TT_4.

[100] Lyons JG, Hallinan M, Kennedy JE, Devine DM, Geever LM, Blackie P, Higginbotham CL. Preparation of monolithic matrices for oral drug delivery using a supercritical fluid assisted hot melt extrusion process. Int J Pharm 2007;329:62-71.

[101] Reignier J, Gendron R, Champagne MF. Extrusion foaming of poly(lactic acid) blown with $\mathrm{CO}_{2}$ : toward $100 \%$ green material. Cell Polym 2007;26:83-115.

[102] Mihai M, Huneault MA, Favis BD, Li H. Extrusion foaming of semicrystalline PLA and PLA/thermoplastic starch blends. Macromol Biosci 2007;7:907-20.

[103] Mihai M, Huneault MA, Favis BD. Crystallinity development in cellular poly(lactic acid) in the presence of supercritical carbon dioxide. J Appl Polym Sci 2009;113:2920-32.

[104] Lee ST, Kareko L, Jun J. Study of thermoplastic PLA foam extrusion. J Cell Plast 2008;44:293-305.

[105] Matuana LM, Diaz CA. Study of cell nucleation in microcellular poly(lactic acid) foamed with supercritical $\mathrm{CO}_{2}$ through a continuous-extrusion process. Ind Eng Chem Res 2010;49:2186-93. 